\title{
ABSTRACTS AND NOTICES FROM THE SCIENTIFIC AND TECHNICAL PRESS No. 6
}

\author{
Issued by the Directorates of Scientific Research \& Technical Development
}

\author{
Aircraft Engines, Fuels and LUbricants

\section{Fuels} \\ Fuels for use in internal combustion engines and for other purposes. (E. G. E. \\ Mayer, E.P. 269222, 3/12/25; cf. E.P. 262363 ; B. I927, 134. J. Soc. \\ Chem. Ind., XIVI., Sept., I927, p. 721.$)$ (8.51/7639 Great Britain.)
}

Liquid hydrocarbons of relatively high b.p. and substantially devoid of constituents boiling below roodeg., and of which $80-100$ per cent. distil over at temperatures up to zoodeg., are used mixed with a small quantity of volatile basic material (e.g., ammonia) and ethyl ether.

Atomisation of fuels in carburettors. (F. N. Scheubel, paper read to W.G.L., Sept., 1927. Z.F.M., XVIII., I $4 / 10 / 27$, p. 448.) (8.53/8384 Germany.)

The lecturer describes experiments carried out in the Aerodynamical Institute of the Technical High School at Aachen. By means of instantaneous photographs the distribution of fuel drops in the carburettor model was investigated. Both the distribution of the drops in the induction pipe as well as their size and speed were measured. The influence of the type of carburettor jet was investigated.

On the size-distribution of colloidal particles. (N. Rashevsky, Phys. Rev., XXXI., Jan., 1928.) (8.51/8364 Great Britain.)

A colloidal solution, which contains particles of various size, is considered to be thermodynamically similar to a solution containing various kinds of dissolved molecules. Planck's expression for the characteristic function of such a solution is then applied. The characteristic function happens in this case to depend on the distribution-function of the size of particles. That distribution is considered actually to occur, which makes the characteristic function an cxtremum, and is determined in the usual way. The theory applies only to dilute colloidal solution.

Production of synthetic fuel. (C. Laillet, A. Chaix and J. Chenail, F.P. 621728, $2 \mathrm{I} / \mathrm{s} / 26$. Br. Chem. Abstr. B., I7/2/28, p. I I 5.) (8.51/8372 France.)

The superheated vapour of a volatile solvent such as acetone, ether benzene, toluene, carbon tetrachloride, petrol, etc., is passed at the ordinary pressure into a closed vessel containing powdered or granulated coal, anthracite, lignite, shale, asphalt, peat, etc., until the temperature reaches $45^{\circ-50 o d e g . ~ T h e ~ s o l v e n t ~ i s ~}$ recovered by evaporation from the liquid extract, and the residue is used as fuel.

Synthetic fuels. (La Rev. Petr., No. 239, 15/10/27, p. 17.) (8.51/767 I France.)

Attention is called to a series of patents taken out recently by the I.G. Farbenindustrie on the question of synthetic fuel. The English numbers of these patents are:-

Pat. No. 26952 I

Pat. No. 269547

Pat. No. 260625

Pat. No. 270040 $\begin{array}{ll}\ldots & \ldots \\ \ldots & \ldots \\ \ldots & \ldots \\ \ldots & \ldots\end{array}$

4th April, 1927.

I2th April, I927.

I th January, I926.

26th February, 1926. 
Taking them in the above order these patents refer respectively to:-

The synthesis of hydrocarbons from $\mathrm{CO}$ and $\mathrm{H}_{2}$.

The conversion of saturated into unsaturated hydrocarbon.

The manufacture of iron carbonyl.

The manufacture of silica gel.

Determination of volatility of gasoline. (R. Stevenson and J. Babor, Ind and Eng. Chem., XIX., Dec., 1927, p. 136r.) (8.53/8376 U.S.A.)

The dew point is the best indication of the temperature of complete vaporisation, under equilibrium conditions, of gasoline alone or mixed with air. This dew point may be determined easily, rapidly, and reliably by means of an optical effect shown by a new device called the " black-surface dew indicator."

The disadvantage of actually determining the dew points of the different air-fuel mixtures may be avoided by the use of a graph showing the relation between the dew point of the gasoline alone at $760 \mathrm{~mm}$. pressure and the dew points of the different air-gasoline mixtures. This equilibrium end point or dew point of gasoline alone is especially easy to determine with the black surface dew indicator, and its relation to the dew points of the air-gasoline mixtures is sufficiently definite for their derivation by means of a graph with practical accuracy.

In this way one simple determination of the dew point of gasoline alone suffices for the deduction of the temperatures of complete vaporisation of all the practical air-gasoline mixtures.

Possible auxiliary sources of liquid fuels. (Prof. A. W. Nash, J. Inst. Pet. Tech., XIII., Oct., I927.) (8.51/8375 Great Britain.)

The following sources for the supply of fuels are considered :-

(I) Power alcohol.

(2) Oil shale.

(3) Low temperature carbonisation.

(4) Berginisation.

(5) Synthetic fuel from carbon dioxide and hydrogen.

With fuel petroleum at its present price, none of the methods given with the possible exception of the destructive distillation of oil shale, appear to be a paying proposition. In the case of the low temperature distillation of coal, the economic value of its by-products is the determining factor. Any alternative system of liquid fuel supply would also have to deal with the production of lubricating oil. In this connection the manufacture of synthetic fuels from carbon monoxide and hydrogen is of especial interest as it also lends itself to the production of lubricants.

Fuel for internal combustion engines. (Soc. Lefrance et Cie., F.P. 622077, 3/4/26. Br. Chem. Abstr. B., I7/2/28, p. II5.) (8.51/8374 France.)

Complex ketones prepared as described in F.P.566, 543 (cf. E.2 I6, I 20 B., 1925,337 ) are added as stabilisers to mixtures of petroleum and alcohol, etc.

Critical review of fuels for aircraft engines. (E. Rackwitz, paper read to W.G.L., Sept., I927. Z.F.M., XVIII., I 4/10/27, p. 449.) (8.51/8365 Germany.)

In addition to the normal petrol and benzol, the lecturer dealt with the following fuels :-

I. Brown coal distillates.

2. Doped petrol.

3. Alcohol and its mixture with petrol and benzol. 
4. Petrol toluol and petrol xylol mixtures.

5. Coal tar derivatives, tetraline, and decaline, either alone or mixed.

6. High boiling-point paraffins and tar distillates.

7. Synthetic petrol. .

Important factors in determining the suitability of a fuel are its resistance towards cold, freedom from corrosion and high flash point.

\section{The production of benzol in France. (La Nature, No. $2767,15 / 8 / 27) \quad.(8.5 \mathrm{r} / 746 \mathrm{r}$ France.)}

In a paper read before the Fuels Congress held at Montpellier on June $17^{\text {th }}$, 1927, M. Georges Kimpflin referred to the recent increase in the production of benzol in France. The output has risen from 10,000 tons in 1921 to 60,000 tons in 1926 , and it is estimated that as a result of the law making the extraction of benzol obligatory, the output will not be long in reaching 100,000 tons. This figure is roughly equal to the amount of benzol France would require for the manufacture of H.E. in a war in which France would be cut off from the help of other countries. This is reassuring from the point of view of the safety of the nation.

As regards the technical aspect of the question, M. Kimpflin pointed out that benzol is the best of all fuels as regards number of useful calories developed per unit of volume, and as regards efficiency of the calorific power. In addition to a high degree of homogeneity and to its antidetonating properties, benzol acts as a solvent in mixtures of alcohol and petrol so that these can be used in engines. even if the alcohol has not been completely dehydrated. The inclusion of benzol in the French "national fuel" is due to this property. M. Kimptlin pointed out that a great mistake was being made in using crude tar for road-making as no. advantage was gained as far as the roads were concerned and an appreciable amount of valuable products such as benzol, naphthaline, phenol and cresols were lost.

Development of synthetic motor fuels. (Autom. Ind., LVIII., Feb., 1928, p. 2 I0.) $\left(8.5 \mathrm{I} / 83^{6} 3\right.$ France.)

The French Government has been carrying out extensive researches on the phenomenon of combustion and the physical and chemical properties of petroleum derivatives. The work is partly carried out in the Government laboratories under Dumanois and partly in the laboratories of the University of Paris. Important work on lubricating oils is being carried out at Strassburg University. The procuuction of alcohol from wood refuse is receiving serious attention. In Algiers and Senegal the leaves of the Sisal Agave furnish appreciable quantities of fermentable sugars, and are being utilised for fuel production. The possibility of using wood charcoal for the generating of producer gas which can be used in lorry engines has received attention and the industry is being heavily subsidised by the French army. The German methanol process, as well as the production of liquid fuel from lignite and shale, is also receiving attention. A special laboratory has been constructed for the study of the catalytic transformation of gases obtained from coal. The work is under the control of a specially created research board working in collaboration with leading industrialists.

\section{Lubricants}

Lubricating power cylinders of Diesel engines. (W. O. Northcutt, Mech. Eng., XLIX., Oct., 1927, p. 1068.) (1 2.81/7669 U.S.A.)

Independently of the base of crude oil from which lubricating oils may be made, oxidation takes place after a certain temperature is reached. If an improper method for applying the lubricating oil to the power cylinder is used, the oxida- 
tion of the oil may be greatly increased. Undesirable products may be formed by oxidation, which increases friction and wear. If the lubricating system were so arranged as to have new clean oil at the inner portion of the cylinder liner for the piston rings to wipe over and spread into a film on the liner walls, then the base of the crude oil from which the lubricating oil is refined would no longer play a predominant part in determining the wear by the oxidation products.

The author describes various schemes for supplying oil in this form and quotes figures justifying his theory.

Lubrication of surfaces under high loads and temperature. (T. E. Stanton, Engng., CXXIV., 1927, pp. 312-313. Abstr. in Chem. Abstr., XXII., I928, p. I60.) (8.41/7862 Great Britain.)

The variation of attitude and eccentricity of a journal and bearing with known difference of radii was made in order to check the hydrodynamic theory. $\mathrm{Up}_{\mathrm{p}}$ to an eccentricity of 0.50 , the agreement between theory and observation is fairly good. Above this value the oil film broke down and boundary lubrication set in. The efficiency of castor oil is due to a low value of the coefficient of friction under boundary conditions. (Abstractor's note: "Boundary lubrication", is defined as lubrication by a layer of oil one molecule thick. It has been rejected by other experimenters and the observed results attributed to local concentrations of lubricant. The physical conception of bearing surfaces perfect enough to allow of a smooth layer of single molecules is hard to digest. Stokes' coefficient of viscosity has no meaning under such conditions.) Mineral oil can be obtained that maintains a film at higher temperature than castor oil. Mineral oils of the same acidity and unsaturation with approximately equal viscosity and density may vary greatly in their ability to stand up under conditions of film lubrication at high temperatures.

Lubricant. (I. G. Farbenind, A-G., G.P. 445116, 23/12/25. Br. Chem. Abstr. B., I $7 / 2 / 28$, p. II2.) (8.41/837 I Germany.)

Finely-divided ferric oxide obtained by the combustion of iron carbonyl is used as a lubricant, either alone or mixed with other substances. The material possesses lubricating properties equal to those of graphite.

Valuation of lubricants. (Chem. and Ind., May, 1927, p. 780 . Abstr. in J. Inst. Pet. Tech., XIII., Oct., I927, p. 246a.) (8.41/7720 U.S.A.)

The article gives a list of the desirable properties of lubricating oils, summarises methods of analysis and indicates some practical methods of detecting the presence of acid :-(I) A sample of oil mixed with cuprous oxide becomes blue or greenish-blue after about twenty minutes if acid is present. (2) Drops of cylinder oil placed on a sheet of copper give a green precipitate after five or six days if acid is present. The best test of an oil is to use it for three or four days in the cylinder, after previous cleaning of cylinder, piston and lubricator. At the end of the test all the parts should be bright, covered with oil and free from deposits of carbon, etc.

Purification of waste lubricating oils. (W. A. Street and H. Hey, E.P. 278434, 6/7/26. Br. Chem. Abstr. B., XLVI., 23/12/27, p. 931.) (8.44/8377 Great Britain.)

The waste oil is diluted with a volatile solvent (e.g., petrol) and finely divided water and solid materials are removed by treatment with a small quantity (0.5-I per cent.) of a reagent made by the action of strong sulphuric acid on oleic acid (cf. E.P. I $76,540:$ B., I922, 334a). The diluted oil is separated from the sludge formed, and treated with concentrated sulphuric acid ( $1-2.5$ per cent. 
by vol.). The oil, after settling, is separated, neutralised with an excess of solid or alcoholic caustic alkali, and run into a still where the solvent is removed by heating with closed steam coils; the heavier spirit and light oils are distilled off in a current of superheated steam at a temperature up to zoodeg. The hot residual lubricating oil, after being mixed with an absorbent decolorising earth ( $\mathrm{I}-2$ per cent.) or active carbon ( 0.5 per cent.), is passed through a warm filter press from which is delivered a clear bright oil of good colour, high viscosity and high flash point.

\section{Thermodynamical Investigations}

On the combustion of carbonic oxide. J. P. Baxter, Phil. Mag., No. 27, Jan., 1928, p. 82.) (8.57/853o Great Britain.)

In an earlier paper (Phil. Mag.; January, 1927) the author arrived at the following conclusions :-

(a) The combustion of dry carbon monoxide probably takes place in two ways-firstly by direct oxidation, and secondly by the intervention of watervapour.

(b) The addition of extremely small traces of hydrogen produces a great acceleration in the speed of combustion, and may alter the method of combustion.

With a view to further investigating the above points, it was decided to carry out a series of measurements on explosions of carbon monoxide and air into which small regulated amounts of water-vapour, hydrogen, and other impurities would be introduced.

Analysis of the products of the combustion shows that as the water-vapour content of the gas is increased, the amount of oxide of nitrogen formed decreases very rapidly. 'This is in agreement with Bone's figures for oxides of nitrogen produced at high pressures which are generally recognised as favouring the direct oxidation theory.

Rudiant heat emitted during gaseous explosions. (C. H. Johnson, Phil. Mag., No. 28 , Feb., 1928, p. 30r.) (8.57/8531 Great Britain.)

When conducting a physico-chemical examination of the radiation from a gaseous explosion, it is very important to discriminate between the emission of radiant energy from the wave-front and that from the hot products of combustion, a point to which little consideration seems to have been given by other investigators. In order to attain the desired result, a long narrow explosion vessel was used in which the rapid cooling of the burnt gases behind the wave reduced to almost negligible proportions the amount of radiation received from that source. A simple method for the calibration of a linear thermopile, necessarily placed at some distance from the bomb, has been described, which enabled a quantitative extension of work detailed in other publications to be made.

The effect of water, and incidentally of other catalysts, upon the emission of infra-red radiation from the wave-front in explosion of carbon monoxide and oxygen had proved to be of considerable magnitude. In particular, an additional seven per cent. of the gross heat of combustion was radiated from a dried gas mixture, in excess of that emitted in the presence of $\mathrm{r} .9$ per cent. of water-vapour.

The slow combustion of hydro-carbon. (M. Stanislau Landa, Comp. Rend., 27/2/28, p. 589 .) (8.57/8548 France.)

The slow combustion of hydrocarbon has been studied specially by Bone, who has formulated a theory of hydroxilation. In order to test this theory the 
author subjected paraffin wax to temperatures of the order of 3 oodeg. C. It was found possible to isolate intermediate products of combustion. Although the results are not yet complete the author is of the opinion that the hydroxilation theory of Bone has been fully established.

Flames and combustion. (Prof. A. Egerton, letter to Nature, CXXI., $7 / 1 / 28$, p. Io.) (8.57/8378 Great Britain.)

Prof. Egerton deals with the mechanism of gaseous combustion.

Reaction will commence when a sufficiently energetic molecule of fuel combines momentarily with an energetic oxygen molecule. A temporary peroxide in a high energy state is thereby formed. Among the several possible changes which may result, starting with a hydrocarbon, a breakdown into an aldehyde and a water molecule is quite a likely one. These molecules would possess not only the initial energy of activation, but also the reaction energy, and on their next encounter with other fuel molecules (or oxygen molecules) could communicate sufficient energy to enable combination to occur and so start a reaction chain. Such a mechanism would explain why the initial stages of combustion are so much influenced by concentration. For example, a small quantity of acetaldehyde added to the pentane makes little difference to the igniting temperature of the pentane, although the aldehyde alone ignites at a lower temperature. The reaction chains facilitating the oxidation of the aldehyde alone cannot be started to the same extent in the mixture, as the collisions with the hydrocarbon molecules communicate insufficient energy to activate the latter. As the temperature rises there is every probability that some ionisation occurs. This is, however, not a primary step. It is the combination of the fuel molecule with the oxygen which is the essential initial process. The effect of an antiknock is mainly that of an inhibitor of oxidation.

Propagation of combustion in gaseous mixtures. (T. Terada and K. Yumoto, Proc. Imp. Acad., Japan, II., 1926, pp. 261-263. Abstr. in Chem. Abstr., XXI., 1927, p. 2986.) (8.57/7635 Japan.)

The combustion of mixtures of hydrogen with air or oxygen has been photographed, the ignition being effected by an electric spark. With a hydrogen-air mixture containing 12.5 per cent. of hydrogen, combustion is at first propagated most rapidly perpendicularly to the electrodes. Later, however, there is some acceleration along the line of the electrodes. With mixtures containing $7-9$ per cent. of hydrogen the wave-front is not symmetrical with respect to the spark. If the electrode consists of parallel fine wires, the wave-front is spherical except along the electrodes. If there is an electrically heated wire near the spark gap, the combustion proceeds along it at a high speed.

Activity of various metals and metal oxide catalysts in promoting the oxidation of methane by air. (W. P. Yant and C. O. Hawk, J. Am. Chem. Soc., XLIX., 1927, p. 1454. Abstr. in Fuel in Sc. and Prac., VI., Oct., 1927, p. 475.$) \quad(8.514 / 7672$ U.S.A. $)$

The experimental results were obtained during an investigation carried out for the United States Bureau of Mines in a search for a catalyst for use in firedamp detectors. The catalysts investigated were uranium oxide, thorium oxide, cerium oxide, platinum black, nickel, platinum and nickel, copper and cobalt, cobaltic oxide and nickel oxide with manganese dioxide, ferric oxide, chromic oxide, and "Hopcalite." The mixtures of methane with air contained about 4 per cent. methane, and the temperature range of the experiments was from I 5odg.C. to 35 odeg. C. Cobaltic oxide was found to be the most efficient catalyst. The results are given in the form of a graph. 
The influence of mixtures of carbon dioxide and carbon dioxide and carbon tetra-chloride vapour on the inflammability of a methane-air mixture. (W. P. Jorisson and G. M. A. Kayser, Rec. Trav. Chim. Pays Bas., XLVI., 1927, p. 373. Abstr. in Fuel in Sc. and Prac., VI., Oct., 1927, p. 475.$) \quad(8.514 / 7673$ France. $)$

The authors have determined the amounts of carbon tetrachloride-vapour and carbon dioxides, which together are necessary to make a 9 per cent. mixture of methane with air non-explosive. The two inert gases were found to have a considerable influence on each other. For example, whereas 9 per cent. carbon dioxide, alone, or 6.7 per cent. carbon tetrachloride, alone, was required to make the standard methane-air mixture non-explosive, the same result was obtained with only 4.5 per cent. of a mixture of carbon dioxide and carbon tetrachloride containing 40 per cent. carbon tetrachloride.

Non-knocking fuel composition. (S. 'P. Marley and W. A. Gruse, U.S.P. I645109, II $/ 10 / 27$. Br. Chem. Abstr. B., I7/2/28, p. I I5.) (8.514/8373 U.S.A.)

An aminoaryl alkyl ether, e.g., p-phenetide $(2.5 \%)$, is added to petrol to inhibit knocking.

Comparison of methods of estimating the anti-knock value of various dopes. (Autom. Ind., Feb., 1928, p. 161.) (8.514/8370 U.S.A.)

The article gives a resumé of a series of papers presented to the Research Department of the American Society of Motor Engineers. Of special interest is an investigation into the possibility of correlating the measurements of the anti-knock values of various fuels determined by various laboratories using different methods. The outstanding conclusions were the following:-

r. There is urgent need for the further development of measurement.

2. It is of the greatest importance that mixture strength, spark setting and speed be specified.

3. The measure of values in terms of mixtures of a reference fuel with benzol or Tetra Ethyl lead is apt to be misleading.

4. The method of fuel rating developed by the Bureau of Standards is favourably commented on. This method consists in comparing the maximum i.h.p. that can be obtained from a single cylinder test engine without knocking.

Explosion of methane with up to its own volume of oxygen at initial pressures up to I 50 atmospheres. (D. T. A. Townend, Procs. Roy. Soc., CXVI., 1/1 1/27, pp. 637-663. Abstr. in Sc. Abstr. A., XXXI., 25/2/28, p. 1 10.) (8.57/8580 Great Britain.)

The results are given of a systematic study of the behaviours on explosion of (I) a number of methane-oxygen mixtures between the limits $5 \mathrm{CH}_{4}+2 \mathrm{O}_{2}$ and $\mathrm{CH}_{4}+\mathrm{O}_{2}$ and (2) of mixtures corresponding with $\mathrm{CH}_{4}+\mathrm{O}_{2}+3.76 \mathrm{R}$ $\left(\mathrm{R}=\mathrm{N}_{2}\right.$, Ar or $\left.\mathrm{He}\right)$. Although at atmospheric pressure it is not possible to explode methane with less than two-thirds of its own volume of oxygen, at high pressures mixtures containing far less oxygen can be readily exploded. Increasing the initial pressure in exploding mixtures containing upwards of 60 per cent. of methane results not only in an increase in the violence of the rexplosion but also in a diminution, and sometimes in the entire prevention, of the deposition of carbon. These results are probably due to the influence of pressure in suppressing the thermal decomposition of methane. Contrary to its behaviour in the explosion of carbon monoxide-air mixtures, nitrogen is not "activated" in the explosion of a $\mathrm{CH}_{4}+\mathrm{O}_{2}+3 \cdot 76 \mathrm{~N}_{2}$ mixture, but appears 
to behave normally as a mere diluent. In comparison with that of argon the influence of helium in the explosion of $\mathrm{CH}_{4}+\mathrm{O}_{2}+3.76 \mathrm{R}$ mixture is to shorten the time taken for the attainment of maximum pressure, as well as to increase the subsequent rate of cooling, these effects being accounted for by the greater mobility of the helium molecule. The corrected values of the ratio of the maximum to the initial pressure are, however, always greater for the argondiluted mixtures. These results furnish general confirmation of the earlier observations and show that the mode of combustion of methane in explosions at high pressure accords well with the hydroxylation theory of hydrocarbon combustion.

Inflammation of paraffin-air mixtures in a closed spherical vessel. (G. B. Maxwell and R. V. Wheeler, J. Chem. Soc., Sept., I927, pp. 2069-2080. Abstr. in Sc. Abstr. A., XXXI., 25/1/28.) (8.57/8579 Great Britain.)

In previous experiments with methane-air mixture, ignited at the centre of the spherical vessel, Wheeler had observed maximum pressures ten per cent. lower than the values calculated on Langer's specific heat data. Tizard and Pye (Empire Motor Fuels Committee Report, I923-24) found that heptane-air mixture gave nearly the calculated pressure values in engines. The new experiments are made in similar apparatus as before with methane, ethane, propane, butane and pentane, which all give similar pressure curves. The maxima increase in the order stated, and approach the calculated value more and more in that order. The observed maxima fall off more rapidly than the calculated as the hydrocarbon concentration increases from 2 to 14 per cent.; the maxima are for methane near ten per cent., for petane near three per cent. The pressure loss is partly due to radiation, but to a greater extent to the low value previously assumed for the specific heat of steam (Bjerrum's value); between $100^{\circ}$ and $2000^{\circ} \mathrm{C}$ the specific heat of steam seems to lie between the values of Bjerrum 8.42 and Womersley 11.69 . The extent of dissociation of the $\mathrm{CO}_{2}$ was probably over-estimated previously. Some of these probable errors would also affect the work of Tizard and Pye. The rate of pressure development would depend upon the calculated mean explosive temperatures.

\section{Heavy Oil Engines}

The Bosch Acro Diesel Engine. (Paper read before 66th Mecting of D.V.L., Mannheim, by L. Hausfelder, Motorwagen, 10/8/27, p. 500.) (1 2.81/855 Germany.)

In the Acro Diesel the combustion space essentially consists of three parts (x) A cylindrical portion incorporated in the piston. (2) An inclined passage which acts as a lid to this first combustion space. (3) A small clearance volume left over between the top of this lid and the cylinder head when the piston is in the dead centre position.

The fuel is injected across this small clearance space through the inclined lid passage into the combustion chamber proper situated inside the piston. The passages are so dimensioned that the fuel meets with the requisite amount of oxygen in the inclined passage, so that combustion starts at this point.

The subsequent burning follows two stage ignition principle. It is claimed that the engine operated satisfactorily at high speed.

High speed Diesel engines for transport purposes. (Dr. W. Riehm. Motorwagen, 29/2/28, p. 89.) (12.81/8581 Germany.)

The author describes the latest development of the M.A.N. solid injection engines both for lorries and small locomotives. According to Dr. Riehm the difficulties of governing the lorry engine have now been overcome and in addition 
to showing a large saving in weight of fuel consumed, the lorry Diesel requires less gear changing than a petrol engine of equal output. This is mainly due to the fact that with decreasing r.p.m. the mean effective pressure of the Diesel increases. As an interesting development the boosted Diesel engine is mentioned; in this way greater elasticity of performance can be obtained without material increase in heat stressing.

On the fuel injection and combustion in the Diesel engine (solid injection). (A. Levi-Cases, Not. Tec., Jan., 1928, pp. I-23, and Feb., 1928, pp. 1-35.) $(1,2.81 / 8532$ Italy. $)$

These articles represent a very useful summary of published researches dealing with the solid injection engine. Special reference is made to experiments by Marker on the Junkers opposed piston engine on the effect of air swirl in combustion. Of interest also is a comparison of the various types of two stage ignition engines. The article is to be continued.

Trunsmission and removal of heat by the cooling system of Diesel engines. (W. Wakefield, Am. Soc. Nav. Eng., XXXIX., p. 514 . Abstr. in Eng. Abstr., Jan., I928, p. I 23.) (12.81/8399 U.S.A.)

In a Diesel engine the greatest outflow of heat from the cylinder is by radiation. Over Io per cent. of the heat of combustion of the fuel passes through the piston. The heat radiated to the metal is greater with large than with small cylinders. A large proportion of the failures of Diesel engines may be traced to neglect of special design to reduce the dissipation of heat to the cylinder walls. The difficulties become specially marked in cylinders exceeding $3^{\circ}$ inches in diameter.

Oil spray research. (Gas, Oil and Power, 4/8/27, p. 238. Abstr. in J. Inst. Pet. Tech., XIII., Oct., 1927, p. 266a.) (12.81/7717 U.S.A.)

The equipment at the Pennsylvania State College for the study of oil-spray research is described. A pressure chamber $28 \mathrm{in} . \times 2$ in. $\times 2$ oin. is used, tested to $800 \mathrm{lbs}$. pressure and fitted with two plate glass windows, one of which is provided with a wiper. Penetration is studied by the impinging of the spray on a pendulum device. Injection, both by automatic and by cam-actuated nozzles, can be studied. The pressure indicator consists of a serjes of diaphragms deflecting at different pressures; at the instant the pressure reaches a predetermined value an electrical contact is made between a diaphragm and a stop and a spark record is made on a rotating drum.

Solid injection 4-strolie oil engines. (R. Mayer, Z.V.D.I., LXXI., p. ro8r. Abstr, in Eng. Abstr., Jan., 1928, p. 124.) (12.81/8398 Germany.)

At the Linke-Hoffman Works, Breslau, a series of four-stroke-cycle, solidinjection oil-engines has been developed which can be built in units ranging from 50 to 1,200 b.h.p. to run at speeds between 167 and $25^{\circ}$ r.p.m. The nozzles of the fuel-valves, which may be up to five in number, are directly shut off by the cone face of the valve needle. The author states that dribbling is absent and that more direct control of the fuel-spray at partial loads is possible than with the more usual type of sprayer. It has been found possible to use holes about twice the usual size, and the resulting indicator diagrams are of the dual-combustion type. The fuel pump is driven through spur gearing directly from the main crankshaft, and experiments have shown that the length of oil-pipe which may attain $7 \mathrm{~m}$. $\left(23^{\mathrm{ft}}\right.$ ) to the farthest cylinder does not affect the injection. 
On the thermal efficiency of high speed Diesel engines (Japanese). (Toyoji Narita, J. Soc. Mech. Eng., Tokyo, XXVIll., 1925, p. 97. Abstr. in Jap. J. of Eng., V.) (1 $2.81 / 7924$ Japan.)

The shape of most indicator diagrams taken from high-speed Diesel engines is quite different from that of the Diesel cycle: i.e., in the latter the fuel burns at constant pressure at one time, while in the former the combustion takes place in two phases. A part of the fuel burns first at nearly constant volume at the end of compression, next the remaining part of it burns at nearly constant pressure at the pressure attained by the former combustion, thus approximating the so-called Sabathe cycle. It is attempted in this paper, first to deduce the formulæ for the thermal efficiency of the said cycle, and next to compare it with that of the Diesel cycle.

\section{Torsional Vibration}

The whirling speed of shafts. (T. M. Naylor, Engineering, CXXIV., 7/10/27, p. 474.) (8.22/7632 Great Britain.)

Experiments are described which show the presence of a decided disturbance in the motion of a rotating shaft at a speed approximately one-half of the true whirling speed. This is in agreement with the mathematical deduction of Prof. Stodola.

Stiffening effect of turbine discs on the strength of the turbine shaft. (Dr. Ing. Bruno Eck, Z.V.D.I., LXXII., I 4/1/28, p. 5 ${ }^{\mathrm{I} .)} \quad(8.22 / 8397$ Germany.)

The author develops a theory for determining the stiffening effect of turbine discs both in the case of integral discs and discs which are keyed on or shrunk on. The theory is of use in determining the critical velocity of complete machines, and indicates how much increase in speed is possible without sacrificing the safety of the plant.

The Olsen balancing machine. (Autom. Ind., LVII., I $7 / 12 / 27$, p. 912.) (8.221/8380 U.S.A.)

The article describes a balancing machine suitable for the rapid testing of engine crankshafts. The crankshaft is supported in two end bearings mounted on vertical pillars which are connected to the base of the machine by means of springs, free to vibrate in a transverse direction. The crankshaft is rotated at a speed of approximately 200 r.p.m. and the direction of unbalanced movement is indicated by means of a spark from a, rotating electrode. The amount of unbalance is measured by the displacement of sliding weights on the supporting standard.

Vibrographs for the determination of vibrations of motor vehicles. (Dip. Ing. Julius Oelschlager, Motorwagen, XXX., 2o/8/27, pp. 520-522.) (8.22/7937 Germany.)

The theory of the measurement of vibrations is developed shortly and four vibrographs are described. The Wiechert compound portable seismograph (recording horizontal and vertical vibrations simultaneously) and the Schlick pallograph are dealt with very shortly, both being heavy and complicated instruments. The first is ultra-sensitive and only useful for scientific research, the second is suitable for slow vibrations only. The next two instruments are described more fully. Dr. Geiger's vibrograph occupies an area of $12 \times 12$ in. and weighs about 14 lbs. The instrument can be adjusted to measure vibrations of a frequency from 50 to 60,000 per min. with amplitudes down to $0.05 \mathrm{~mm}$. It can be used to measure horizontal and vertical vibrations, also deformations or elongations of frames, springs or ties on running vehicles. The vibration 
indicator patented by Thyssen is a more simple instrument on the same principle, giving direct readings of the principal direction of the vibration, the amplitude and the frequency. The instrument only records the principal vibration, those of a higher order are not recorded by the instrument.

\section{Mechanical and Heat Losses}

Distribution and oscillation of the temperature in the principal parts of an aeroplane engine. (T. Suhara, IV. Int. Air Cong., Rome, Oct., 1927.) (8.64/7898 Italy.)

During these experiments the temperature of 35 important parts of the engine was noted by means of a thermograph composed of thermometric elements connected up to a galvanometer whose oscillations were photographically recorded three times a second. Of special interest are experiments showing the effect of interrupting the cooling water and running with the engine dry.

\section{Heat transfer. (N. Jacob, Z.V.D.I., 10/3/28, p. 34r.) (8.64/8533 Germany.)}

The V.D.I. has formed a special committee for the investigation of thermodynamic problems. A symposium of papers on heat transfer was considered early in January, 1928, when papers under the following four headings were discussed:-

I. Heat transfer without change of state.

(a) By natural convection.

(b) By artificial convection.

2. Heat transfer with change of state.

(a) By conduction.

(b) By artificial convection.

3. Heat radiation.

(a) Total radiation.

(b) Distribution through a spectrum.

4. Review of foreign literature.

The experimental results are generally in good agreement with the theories of Musselt. The papers will eventually be published in full Forsohungsarbeiten of the V.D.I.

Experiments on wear under sliding and rolling friction. (E. Heidebrock, Maschinenbau, VI., 1927, pp. 983-991. Abstr. in Phys. Ber., 15/1/28, p. I3I.) (Io. I I $/ 834$ I Germany.)

The author designed a special machine which enabled him to study the wear by direct loss of weight of the parts experimented on. For cast iron rubbing on cast iron or against steel the wear was found to be proportional to $P^{\text {n }}$, where $n$ varies between 1.3 and 3 , depending on the quality of the iron, $P$ being the load. The specific wear of $Q / P$ was found to remain constant up to a certain critical value of $P$ in the case of cast iron rubbing on cast iron. Cast iron rubbing on steel gives the value of $Q / P$, which increases with $P$ from the start. Examination of the rough surfaces showed that the wear causes a roughening of the surface in the form of ripples.

On the radiation from the inside of a circular cylinder. (H. Buckley, Phil. Mag., IV., Oct., I927, p. 753.) (8.35/7675 Great Britain.)

An expression derived for the radiation from one annulus to any other annulus is used to determine the radiation from any point inside an infinite circular cylinder of uniform temperature, a multiple reflection of radiation heing taken into account. 


\section{Supercharging}

The Sulzer system of supercharging. (J. Am. Soc. Nav. Eng., Feb., 1928, p. I 5 I.) $(8.62 / 8545$ U.S.A.

In the normal Sulzer two-stroke engine two rows of scavenging ports are employed placed one above the other. Normally these ports are connected together to the scavenging air receiver, the top row of ports, which uncovers before the exhaust ports, being insulated from the scavenge air by a flap valve. Only when the engine pressure falls below the scavenge air pressure does the flap valve allow the scarenge air to enter the engine through this series of ports.

The second series of scavenging ports being only uncovered later in the stroke are connected permanently to the scavenging air. In order to supercharge a two-stroke engine of this type, Messrs. Sulzer have fitted a mechanically operated valve in the passage leading to the first series of ports. This valve opens on the upstroke of the piston when the exhaust ports are covered and admits high pressure from the supercharger.

As the time of opening is short, boost pressures of the order of ro $1 \mathrm{bs}$. have to be employed in order to get reasonable increase in charge weight. The test shows that an increased output of 20 per cent. can be obtained without diminishing the reliability of the engine. Tests on a single cylinder show that whilst the unsupercharged engine could develop r, 400 h.p. at a fuel consumption of rgo gms./b.h.p./hr., under boost conditions I, 800 h.p. could be obtained for a net fuel consumption of $200 \mathrm{gms}$./b.h.p./hr.

Recent development problems of aeroplane engines, with special reference to high altitude. (Dr. Ing. Kamm, paper read to W.G.L., Sept., 1927. Z.F.M., XVIII., I 4/10/27, p. 448.) (8.52/8383 Germany.)

For altitudes up to 12, oooft, the lecturer considers the over-dimensioned and super-compressed engine as the simplest solution. By means of blowers it is theoretically possible to reproduce ground level pressure up to an altitude of 90,oooft. The weight-power ratio of the plant becomes, however, excessive, and for a mechanically operated blower an altitude of $5^{\circ}$,oooft. is considered the practical limit. With a pure exhaust drive for the blower this altitude is reduced to 30, oooft. With a combined blower drive, partly mechanical, partly exhaust, this altitude is raised to $60,000 \mathrm{ft}$.

\section{Engine Design}

Splitdorf aircraft magneto, model V.A. (Aviation, XXIII., 3/10/27, p. 81г.) (8.91 $/ 7^{6} 5^{2}$ U.S.A.)

The Splitdorf Electrical Co., of Newark, N.J., has recently brought out what is called the Model VA aircraft magneto. The device consists of two independent ignition units arranged in a single assembly. It is essentially an aircraft magneto design to be mounted vertically in the Vee of the engine, in such a way that those parts that require frequent inspection are readily accessible.

The VA double aircraft magneto is of the inductor type, producing four double sparks per revolution. It consists of a frame, top plate, bottom plate, rotor, breaker housing and magnets. Cast into the top and bottom portions of the frame on opposite sides are four separate coil poles, it being understood the other sides carry the magnet poles. The coil poles are bridged on each side by the laminated " $U$ " shaped coil cores, the centres of which carry the usual primary and secondary windings commonly used in high tension magneto construction. 
High compression and wing radiators. (U.S. Army and Navy Register, 8/10/27.) $(5 \cdot 39 / 792$ I U.S.A.)

The successful performance of the plane piloted by Lieut. H. A. Johnson,

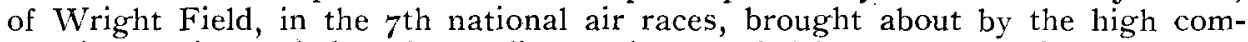
pression engine and the wing radiators, is regarded by some as a forceful argument in support of some airplane engine experts that this combination should be encouraged and developed. It does not matter, it was contended, whether the high compression engine can withstand as much hard work as the normal power plants or that the wing radiators are more vulnerable to enemy fire, so long as the great advantage in speed is in hand.

The new Krupp reduction gear. (Motorwagen, 10/3/28, p. 146.) (8.84/8529 Germany.)

This interesting gear consists essentially of four parts, three internal rollers, enclosed in a circular ring. The internal rollers are accurately circular and the sum of their diameters is slightly larger than the internal diameter of the encircling ring. The centres of the internal rollers are placed in one line, the roller of the largest diameter being placed in the middle. The gear is essentially a reduction gear, which means that one of the smaller rollers is the driven member, the larger central roller transmitting the drive at a reduction speed depending on the ratio of the diameter of the two rollers. During operation of the gear the external ring, being of smaller diameter, undergoes the displacement which causes the internal rollers to be pressed together.

Ring and rollers are so dimensioned that up to maximum load no slipping occurs. It is stated that the efficiency of the gears is of the order of 98 per cent, and its cost of production is considerably cheaper than a normal tooth gear. The gears have been built to transmit up to $200 \mathrm{~h}$.p. with reduction ratios up to $15: \mathbf{I}$.

\section{Self-aligning piston. (Sc. Am., March, I928, p. 254.) (8.24/8546 U.S.A.)}

A new form of piston is described in which a large ball takes the place of the normal wrist pin. This permits the piston to rotate within the cylinder, and it is claimed that this results in a more even wear and lower friction. The ball is rigidly attached to the connecting rod and fits into a hemispherical cup forming part of the top portion of the piston. The piston skirt is separate and forms the lower hemispherical cup for retaining the piston ball. The skirt is spigotted into the piston proper and retained in position by means of four bolts.

The principle of similarity in the design of engine crankshafts. (E. A. Vedemeyer, Motorwagen, XXX., 20/1 I/27, p. 679.) (8.22/8385 Germany.)

Starting with a crankshaft of given dimensions, the author investigates consecutively the effect of :-

1. Alteration of piston and connecting rod mass.

2. Alteration of stiffness.

3. Alteration of fly-wheel mass.

The treatment throughout is elementary.

Petrol filters. (K. R. H. Pretorius, Motorwagen, CLXXXVI., 20/2/28, p. 74.) $(8.542 / 8386$ Germany.)

The article, which is to be continued, describes about a dozen types of petrol filter. Of special interest is the filter proposed by Seppeler. The wire gauze employed in this filter is in the form of a strip which is wound round a slotted drum and kept in position by means of a spring. The fuel passes from the 
outside to the inside of the drum and provision is made for settling space. The filter is easily cleaned as the strip can be totally removed and brushed on both sides.

Engine starters. (Dip. Eng. F. Gosslau, Z.V.D.I., LXXII., 4/2/28, p. 143.) 8.82/8396 Germany.)

The author describes fully the various types of starting mechanisms for aero engines employed at the present moment. Amongst the apparatus mentioned are the following:-

1. Mixture suction pump made by the firm Maybach Motors.-This is a very reliable starter but can only be used in conjunction with special engines, since in its operation it requires the lifting of all the valves.

2. Cartridge starter made by the firm Farman.-Not much is known about this starter. It probably has a deleterious effect on the engine.

3.-Electric starters. - These are very reliable but suffer from great weight. They only become feasible in multi-engine planes when one central starting battery can be employed.

4. Compressed air starters.-These starters depend on the presence of an air bottle. They are thus only feasible where an efficient ground organisation renders recharging possible.

5. Mixture pressure pump.-This has been developed chiefiy by the French firm Saintin and is a development of the Maybach system. In this case the carburetted mixture is supplied to the engine under pressure, hand or foot pump being employed.

6. Starter of the Société de Mécanique Nouvelle.-In this starter the mixture is not fired in the engine proper but a subsidiary starting engine is used. The mixture is first compressed in the starting engine by means of a hand pump. The starting magneto fires the mixture in the starting engine and immediately afterwards in the main engine.

7. The Bristol gas starter.

8. Flywheel starters. - These have been developed specially in America.

The following weights are of interest:-

I. Compressed air starter with two bottles, $3^{1} \mathrm{~kg}$.

2. Bristol gas starter, $25 \mathrm{~kg}$.

3. Electrical starter type Farman, $38 \mathrm{~kg}$.

4. Flywheel starter with manual operation $12 \mathrm{~kg}$., with electric motor $50 \frac{1}{2} \mathrm{~kg}$., with battery $5 \mathrm{I} \mathrm{kg}$.

The author concludes that there is no satisfactory starter available at the present moment.

"Carlen" silencer for aero engines. (Tedens, I I/2/28,) (8.72/8275 Norway.)

A Norwegian engineer, Carlen, has invented a silencer which has just been tested by the Norwegian Military Air Service experts.

It is possible that in future a silencer will be fitted to each cylinder. The present invention silenced 90 per cent. of the noise of the 120 h.p. Mercedes engine to which it was applied. The apparatus weighs 9 to ro $\mathrm{kg}$, only 20 r.p.m. of the I, 400 r.p.m. being lost.

Sparking plugs. (G. Mickel, Eng. Pat. 279388. I11. Off. J. Pats., No. 2030, $14 / 12 / 27$, p. 6205.) (8.92/8382 Germany.)

Cooling is promoted by forming an annular groove in the insulator, and adjacent openings in the casing. An external sleeve regulates the degree of 
opening. Between the inner parts of the insulator and casing a sleeve of copper, . aluminium or similar material is interposed.

Gyroscopic analogies with electric motors. (B. Salomon, Comp. Rend., CLXXXVI., 6/2/28, pp. 358-36o.) (21.2/8387 France.)

The equations are given for a system of gyroscopes converting pulsations of constant frequency into a continuous torque of variable frequency.

Stresses due to shrinkage of one hollow cylinder on another. (Iwazo Nakayama, J. Soc. Mech. Eng., Tokyo, XXVIII., 1925, p. 96. Abstr. in Jap. J. of Eng., V.) (Io.6I/7923 Japan.)

The equations for stresses and displacements of single or compound cylinders under uniform pressure are deduced from the stress function $F$ which satisfies $\nabla^{4} F=0$, and the axial displacements or axial stresses are easily calculated. Next the effects of the force in the axial direction at the junction of compound cylinders due to cooling contraction are considered in terms of Bessel functions which satisfy $\nabla^{4} F=0$, and numerical examples are offered.

\section{Two-Stroke Engines}

Investigation of the high speed two-stroke engine. (Holm, Motorwagen, XXXI., $31 / 1 / 28$, p. 43.) (8.87 $1 / 8388$ Germany.)

The author points out the importance of giving the exhaust and scavenging ports on two-stroke engines sufficient length. Only under these conditions is it possible to obtain high speeds. It may be necessary to sacrifice over half the stroke of the engine, but even then it is the opinion of the author that the twostroke fitted with a suitable blower and operating at high speeds is the engine of the future.

\section{Triple Chamber Engines}

The Borner triple chamber engine. (A. Borner, Maschinen-Konstructeur, LX., 31/10/27, pp. 474-476.) (8.14/8369 Germany.)

An engine of very unconventional design has recently been developed by A. Borner, an engineer of Dresden, Germany. This engine consists of a cylinder divided into what amounts to three independent combustion chambers with two pistons connected by a rod and arranged in such a manner that the upper piston is substantially double acting while the lower is single acting. An essential feature of the engine is that the interconnecting piston rod is ooil-cooled. Each of the three chambers is equipped with its own admission and exhaust valves and its own spark plug. Each works on the four-stroke cycle, but their combination, particularly for a multi-cylinder engine, is quite involved, and, for example, in a four-cylinder engine is equivalent to that of a 12 -cylinder engine of the conventional type. It does not appear that any such engine has actually been built, and no data of operation are presented. The inventor is well known, however, in German engineering circles.

\section{AERodynamics and Hydrodynamics}

\section{Fluid Motion}

On the interference effect of body and wing. (J. Lennertz, Z.f.A.M.u.M., VII., I927, p. 249.) (5.32/7883 Germany.)

In Z.V.D.I., LXXI., I9/1I/27, p. 1657 , the author furnishes an abstract of the above papers. Using the Prandtl theory an expression is obtained for the interference between body and wing, the body having the simplified form of an 
infinite cylinder whose axis is in the direction of motion. The results are an approximation to the conditions existing for aeroplane bodies of great length, and also would apply to airships. In addition to the total forces acting on the aircraft the distribution of the forces both across and along the wing are important. Assuming an infinitely long body of constant cross-section the forces are in the nature of a lift and there is no resistance. It is of interest to notice that the body does not necessarily cause an increase in the resistance of the wings and that a monoplane of the parasol type may have a similar resistance to that of the low-wing aeroplane of the Junker type.

The author deals next with the minimum induced resistance of the wings for a given total lift. This causes a distribution of lift across the width of the wing corresponding to the elliptical distribution for a wing without body. The proportion of lift contributed by the body has been calculated by the author; its distribution along the body has also been investigated. Experimental investigations concerning the interference of body and wing so far cover only the relationship between the total lift and the resistance of the aircraft. It is thus not possible to test the conclusions experimentally.

Uniform rotation of a rigid body in an unlimited fluid. (B. Caldonazzo, Rep. of the Conference at Innsbruck, 1922, pp. 175-185.) (5.32/8349 Germany.)

The special case is discussed of a very long rectangular lamina rotating about an axis parallel to its long side in a perfect incompressible fluid, initially at rest. Steady motion can only be represented with respect to moving axes, and Bernoulli's equation takes a more generalised form.

Assuming symmetry in parallel planes at right angles to the axis of rotation, the problem becomes two-dimensional and complex algebra offers the most convenient analysis for the solution of the differential equations of motion.

Complex expressions are obtained for the potential and stream functions, hence for the velocity and pressure fields and for the resultant force and moment.

When the axis is very far from the lamina the case reduces to linear motion. By superposition rotation about an edge is obtained.

The flow round a plane lamina in rotation (in an unlimited perfect fluid). (E. Carafoli, Comp. Rend., CLXXXIV., 28/3/27, pp. 804-7.) (5.33/83 18 France.)

The results obtained by Caldonazzo are generalised for the case where there is cyclic flow round the plate initially.

The expression"for velocity, resultant pressure and moment contain additional terms with the constant of circulation as a factor.

This paper and Caldonazzo's paper (see previous abstract) are of importanice as a first step in establishing a hydrodynamical theory of the rotary derivatives, on the lines of the circulation theory of lift.

Three-dimensional disturbance of Poiseuille's flow. (T. Sexl, Ann. d. Phys., LXXXIV., 1927, pp. 807-822.) (5.32/8345 Germany.)

The author showed in a previous paper (Ann. d. Phys., LXXXIII., I927, p. 835) that the stability conditions for lamina flow with paraboidal distribution of velocity are identical with the conditions for lamina flow between plane walls with parabolic distribution of velocity. He then proceeds to superpose on Poiseuille flow a disturbace flow which is symmetrical about the axis, and infers that in no case can such a small disturbance produce instability. The writer considers further flow between parallel walls and classifies the correct analogies between this type of flow and Poiseuille flow. No solution of the various mathematical problems is obtained. 
The boundary layer theory of Prandtl. (Prof. Ahlborn, paper read at meeting of W.G.L., Z.F.M., XVIII., I4/10/27, p. 448.) (5.32/8347 Germany.)

The author criticises almost every point in Prandtl's explanation of fluid flow as in contradiction with facts of observation.

Prandtl thereafter showed the film (displayed for the first time at the Royal Aeronautical Society, May, 1927) in evidence of the substantial correctness of his views.

Professor Tanakadate also showed a film of air flow round wing profiles with and without slots.

Notes on resistance to flow of viscous fluids. (Kyoji Suyohiro, J. Jap, Soc. N.A., $3^{6}$, 1925. Abstr. in Jap. J. of Eng., V.) (5.32/7996 Japan.)

According to the author's view, even when the flow of a viscous fluid becomes turbulent, a thin layer close to the boundary walls persists in lamina How. The thickness of this stable layer is likely to be self-adjusting to conform with the condition for uniform shearing motion; the larger the mean speed of the eddy flow the thinner will be the thickness of the layer. From Orr's and Reynolds' numbers for the critical speed of flow between parallel walls the author has calculated the probable thickness of the layer, and therefrom the resistance to flow of a viscous fluid in a pipe.

To confirm his view the author carried out an experiment after Reynolds' method, with the slight modifications that in his case, a glass pipe was placed vertically and two coloured filaments were let into the pipe, one at the centre and the other close to the wall. He confirmed that even when the turbulence started in the central part, the flow close to the wall remained lamina.

Notes on the variation of pressure and of the variations of velocity in a viscous fluid. (M. Giraul, IV. Int. Air Cong., Rome, Oct., I927.) (5.32/7903 Italy.)

In a perfect fluid the relation which the pressure bears to the velocity is given by the theorem of Bernouilli. If, however, the fluid is viscous, the theorem is exact as regards the greater part of the field, but not so near the body, where the velocity decreases rapidly until it vanishes on contact with the body itself. Generally, it is admitted that this stratum of zero velocity transmits the pressures.

The author starts from the differential equations of motion of a viscous fluid. It is found that an upper limit can be assigned to the correction for the data taken from the theorem of a perfect fluid. For wings, this correction will be considerable on the back near the leading edge, precisely where the theory of Joukowski does not agree with actual practice.

A case of steady flow of a gas in two dimensions. (S. Lees, Proc. Camb. Phil. Soc., XXII., I924, pp. 350-362.) (8.571/797I Great Britain.)

The author assumes the pressure as a function of density-in particular the adiabatic relation-and eliminates $p$ from the two-dimensional equations of a non-viscous fluid.

A first integral gives the resultant velocity in terms of the density, the physical constants of the gas and the initial pressure. The components of velocity are then obtained separately.

On assuming an arbitrary function, an isopotential surface is defined and streamlines can be drawn for the whole field.

A simple example in polar co-ordinates is given. 


\section{Mathematical Theory of Aeroplane Stability}

The dynamics of aeroplane flight. (L. Hopf, Report of the Innsbuack Conference, 1922, pp. 192-210.) (7.2/7972 Germany.)

The problem of longitudinal stability is discussed in a physical rather than mathematical sense and the conclusions are given, without the detailed mathematical analysis, in graphical form showing regions of stable, neutral and unstable equilibrium in the speed incidence plane.

The author then discusses lateral stability and at some length spinning. Wue acknowledgment is made to Bairstow and to English experimental pilots, for elucidating the relation between auto-rotation at mean stalling incidence and spinning. This accounts for equilibrium of the moments about the longitudinal axis.

The author points out that this is not sufficient to account for equilibrium about the cross axis (pitching axis) and proceeds to investigate the gyroscopic couple which he finds necessary and sufficient to account for the observed equilibrium.

The author claims priority for this result.

On Graeffe's method for complex roots. (S. Brodetsky and G. Smeal, Proc. Camb. Phil. Soc., XXII., Pt. II., May, 1924, pp. 83-87.) (7.2/7973 Great Britain.)

Graeffe's method becomes in general inordinately tedious when more than one or two pairs of complex roots exist.

Runge partially removed the difficulty by transforming to another origin in the complex plane, but ambiguities remain in the selection of corresponding moduli.

This difficulty is overcome by transformation to an origin at an infinitesimal distance from the first origin. An example is selected from Bairstow's chapter on aeroplane stability to show the advantage of the new method, and a still more difficult example an octic with four pairs of conjugate complex roots is solved, the tabulated arithmetic occupying only eighteen lines.

Calculations on the setting in of spinning. (A. v. Baranoff, paper to W.G.L., Sept., 1927. Z.F.M., XVIII., I $4 / 10 / 27$, p. 449.) (5.3 I5/8355 Germany.)

By a worked out example which follows the passing of an aeroplane into a spin, the course of the phenomenon is discussed, and the means of hastening or hindering it.

Besides the moment of inertia which depends on the distribution of mass, a tail heavy moment is set up when rapid rotation carries the aeroplane from skidding outward to side-slipping inwards. When the lateral oscillations are heavily damped, the passage into a spin is more difficult.

With weak damping of lateral oscillations by the stabilising fins a so-called variable spin takes place with a characteristic periodic change of path. In conclusion a static criterion for spinning is given, from which it is clear that the discontinuity of longitudinal moment at high incidence, is the effective cause.

\section{Experimental Aerodynamics}

Systematic investigation of Joukousky profiles. (G. Laew, Z.F.M., XVIII., 28/1 I/27, pp. 517-522.) (5.32/8547 Germany.)

Joukowsky profiles have properties dependent on geometrical parameters. The paper gives iso-curves of profile resistance, centre pressure, gliding ratio and climbing coefficients for different parameters. 
An immense amount of numerical reduction of experimental results is involved, with corresponding economy of time to future users.

The distribution of loads between the wings of a biplane having decalage. (R. M. Mock, N.A.C.A. Techl. Note No. 269, Nov., 1927.) (5.33/7930 U.S.A.)

It is known that in a biplane the load is not distributed equally between the wings. The presence of one wing will affect the lift characteristics of the other wing. A designer must know the total load each wing carries in order that he may design an adequate structure.

The purpose of this thesis is to determine the distribution of loads between the wings of a biplane at various angles of decalage, when the gap/chord ratio is one and there is no stagger.

Since the distribution of loads between wings is the ratio of the lift of one wing to the lift of the other, the effective lift of each wing will have to be determined. This can be calculated if the effect of the presence of one wing on the lift of the other wing is known. The effective lif $t$ of each wing was first investigated, using the vortex theory and later by experiments in the wind tunnel. To eliminate a possible source of error, two aerofoils were used, namely, the U.S.A.27 and the Gottingen $3^{87}$. Extensive tests were made, using the U.S.A.27 airforl, and when the results showed a possible error they were checked with the Gottingen 387 airfoil.

The author is indebted to Professor Alexander Klemin and Mr. Frederick Knack for their many helpful suggestions on the theoretical calculations, on the relative values of the vortex theory calculations and on the wind tunnel results.

Approximate calculation of lift and pressure distribution in wing lattices. (M. Schilhansl, paper read to W.G.L., Z.F.M., XVIII., $14 / 10 / 27$, p. 449.) $\left(5 \cdot 336 / 835^{\circ}\right.$ Germany.) lattices.

Reference is given to previous work on circular lattices and rectilinear

The question is discussed of avoiding cavitation in water turbines which is prominent in modern design.

Experiments with aeroplanes of the Canard type. (W. Klemperer, Flugsport, $14 / 3 / 28$, p. 107.) $(5 \cdot 322 / 8537$ Germany.)

The atthor describes model and full-scale experiments with this type of aircraft dating back to the year Igr $\mathbf{I}$. The special aerodynamic features of this design are referred to. The author is of the opinion that this type lends itself especially for flying boats and the article includes a tentative design. It is well known that the Canard type presents difficulties in undercarriage construction when applied to land aircraft. These difficulties are largely overcome in the flying boat.

Full-scale tests in the new N.A.C.A. wind tunnel. (U.S. Air Services, March, I928, p. 40.) $(5.322 / 8544$ U.S.A. $)$

The article describes full-scale drag tests on the Sperry Messenger airplane. The drag of the fuselage, engine, cockpit, wind shield, tail surfaces and landing gear have been computed at speeds between 50 and roo m.p.h., the width of the air stream being zoft. The test showed that the engine (three-cylinder Lawrence radial air-cooled) nearly doubled the drag of the bare fuselage and the drag of 
the landing gear was about the same as that of the fuselage and engine combined. For a total drag of $65 \mathrm{lb}$. the following tables gives the sub-division :-

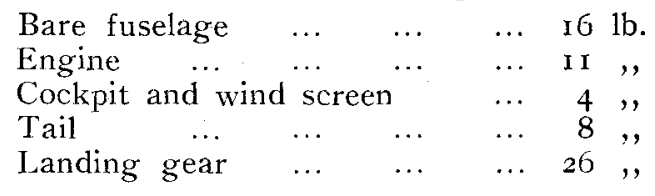

\section{Mathematical Hydrodynamics}

Wave resistance. (T. H. Havelock, Procs. Roy. Soc., A. 1.18, No. A. $779,1 / 3 / 28$, pp. 24-33.) (5.32/8549 Great Britain.)

The author discusses the known results for a two-dimensional doublet at a given depth below the free surface as souree of wave making. He then discusses a horizontal doublet, horizontal doublets in a vertical plane and a general distribu= tion of doublets. With a finite depth the method of images leads to the appropriate expression for wave resistance, as a definite integral of a function of hyperbolic functions.

The water resistance of hulls. (F. E. Fournier, Comp. Rend., CLXXXV., I/8/27, pp. 317-321.) (5.341/7460 France.)

The investigations are restricted to ship's hulls. In developing an expression for the water resistance, the author uses a factor to express the reaction on the hull of the wave formation. He finds that this factor varies very differently according to the fineness ratio of the wetted area. An expression is given for the hump speed, when two formulæe are developed for speeds exceeding the hump speed and for fineness ratio larger and smaller than unity. He gives reasons for the observed fact that the induced waves are always causes of loss above hump speed, whereas the contrary holds good below hump speed when the fineness ratio is smaller than unity; he finally develops two new formulæ which given the most economical conditions for the hull shapes under consideration.

\section{Experimental Hydrodynamics}

Motion of a viscous liquid between coaxial cylinders. (J. W. Lewis, Procs. Roy. Soc., A. I 7 , No. $777,2 / 1 / 28$, pp. $3^{88-406 .) ~(5 \cdot 32 / 8525}$ Great Britain.)

An extension of G. I. Taylor's experiments. The experimental results are summed up in figures I2-I5, which show clearly the difference of critical velocities in passing from steady $u-v$ motion to motion with transverse $u-u$ motion superposed and vice-versa.

The existence of similar upper and lower critical inflow in a straight circular pipe is recalled, and the author concludes that a finite disturbance is required to initiate instability.

\section{Performance and Testing}

Flying boats in a seaway. (F. Z. Diemen, paper read to W.G.L., Sept., 1927. Z.F.M., XVIII., I4/10/27, p. 448.) (5.34I/8357 Germany.)

The relation between wind and waves is first discussed. The stability or flying boats only with stabilising organs near the hull or with stable hulls, is discussed.

There are two principal cases.

First, when the velocity of the boat through the water is small.

Second, when large, in both cases in comparison with the wave velocity, $e . g$. , at starting and at landing. 
The properties of the flying boat at the start in a seaway are discussed, and relation between motion of wave and of hull, with determination of the stresses impressed on the boat.

Finally the boat form is discussed, with examples of Dornier Metall booteconstruction, illustrating the relative merits of keeled and flat bottom construction.

Determination of wing characteristics from flight performance. (Huguenard, Magnan and Sainte-League, Comp. Rend., CLXXXIV., 28/3/27, pp. 802804.) (4.2/835 I France.)

The method of recording flight by cinematograph record through a ruled screen has been referred to in "Abstracts No. 3, p. I4, ref. 5.26/5534," and "Abstracts No. 4, p. I5, ref. 4.2/5788."

The present paper gives the formulæ used in reduction. The agreement with instrumental records of veloctiy and acceleration lay within 1.5 per cent.

Generalised co-ordination of the mechanics of fight. (H. Helmbold, Z.F.M., XVIII., 28/I I/27, Pp. 516-517.) (4.2/8540 Germany.)

A generalisation of Schrenk's power-speed diagram by the introduction of power and velocity ratios. The arbitrary constant power selected is :-

(Weight/eff. span) $)^{1.5}$ (surface $\times$ vertical velocity component) 0.25 (density) ${ }^{-0.5}$.

The arbitrary constant velocity is the velocity at minimum gliding ratio.

\section{Helicopters}

Helicopters. (Sandi Kawada, Research Inst., Tokyo Imp. Univ., 13-15, I925, 274-293, $3^{21-3^{28}}$ and $379-3^{8} 3$. Abstr. in Jap. J. of Eng., V.) (17.24/7945 Japan.)

In the first part a theory of an airscrew at a fixed point is developed-which, strictly speaking, only holds when the circulation is uniform.

This being an extension of the author's previous paper on the theory of airscrews, it is based on the conception of vortex.

A remarkable result obtained is the independence of the effective angle of incidence with respect to the rate of revolution.

The second and third parts consist of the dynamics of flight of helicopters. Horizontal flight and climbing are here investigated.

The following conclusions have been reached:-

(i) The resistance of a helicopter to horizontal flight is very small and a slight inclination of the axis of the airscrew will suffice to overcome the resistance.

(ii) A helicopter having moderate power and dimensions will possess tolerable height of ceiling and climbing speed.

(Abstractor's Note.- The author does not take into account the structuràt difficulties.)

\section{Wind Tunnels and Test Tanks}

Improvement of flow in wind channels. (C. Wieselberger, J. Soc. Mech. Eng., Tokyo, XXVIII., I925, p. 98 . Abstr. in Jap. J. of Eng., V.) (II.II/7927 Japan.)

The most important aerodynamical qualities that should be aimed at in wind tunnel design are as follows:-(I) Constant and parallel direction of flow; (2) uniform velocity across all sections; (3) absence of turbulent motion; (4) constant velocity of flow. 
The Göttingen type of wind tunnel with a parallel part before the working section, of which the section is steadily reduced, realises in a high degree all the above-mentioned qualities. It is shown that this system can easily be applied to other wind tunnels, for instance the N.P.L. or Eiffel types. An Eiffel tunnel of I.25 m. diameter, which was ultimately constructed with a design based on this principle, gave very satisfactory results.

A serious inconvenience in open aerodynamic tunnels. (E. Herrera, IV. Int. Air Cong., Rome, Oct., 1927.) (II.1r/7904 Italy.)

It has been remarked that the large aerodynamic tunnels of the Belgian Aerodynamic Laboratory and of the Technical Service of the French Air Ministry, show a vortex which originates on the ground before the intake crosses the experimental chamber notwithstanding the diaphragm and disappears in the airscrew.

This phenomenon appears only in open tunnels.

In the Aerodynamic Laboratory of "Quatro Vientos" this vortex has never appeared in the large closed tunnel of three metres diameter, but only in the models of open tunnels at a certain distance from the floor.

The author infers that open aerodynamic tunnels always have this serious defect, and that new tunnels should be constructed on the closed principle.

Wave-making apparatus for test tanks. (Z.V.D.I., LXXI., 13/8/27, p. I 168.) (Io.3r/7936 Germany.)

The Hamburg Shipbuilding Laboratory has recently acquired a wave-making apparatus in order to allow of tests on models being carried out in rough water as well as in smooth water as heretofore. The essential part of the apparatus is a metal body rounded off at the bottom forward so that waves are produced . only in front of the apparatus when the body is raised and lowered in the tank. The motion provided by an electric motor, is imparted to the body through three vertical supports sliding within brackets via trains of gearing and two systems of levers and links. The height of the waves can be varied at will up to $30 \mathrm{~cm}$. with a length of five metres. The frequency of the waves can also be varied.

If the moment of inertia of the model is carefully adjusted by means of trimming weights, so that it corresponds exactly according to the law of similarity to the moment of inertia of the full-scale constructions, tests can be carried out to determine whether comcidence exists between the natural period and an: of the periods of the waves. The information gained in this way will enable the designer to avoid coincidence by a suitable distribution of the weights.

\section{Aircraft DEsign and EQUIPMENT}

\section{General Design}

Device to reduce the landing speed of aeroplanes. (E. Heinkel, G.P. 439505/b.16, Flugsport, XIX., I6/2/27.) (7.17/764I Germany.)

In this system the end of the longitudinal rod of the usual control system is articulated in such a way as to allow of alteration of the setting of the ailerons being obtained.

The starting of heavily-loaded aeroplanes. (A. Proll, Z.F.M., XIX., 28/1/28, p. 25.) (7.17/8356 Germany.)

In order to reduce the taking-off distance of heavily loaded aircraft, the : author puts forward proposals of which towing and catapulting are the most practicable. Some of the suggestions seem far fetched. 
Edo all-metal seaplane floats. (B. V. Korvin-Kroukovsky, Aero Digest, XII., Jan., 1928, p. 46.) $(5.27 / 8358$ U.S.A.)

The Edo all-metal floats are built of dural sheets riveted together and suitably stiffened by means of a dural framework. The problem of corrosion has received special attention; proper heat treatment is necessary if the material is to stand up, and it was found that complicated forms requiring bumping or hammering reduced the resistance to corrosion. Such forms were therefore eliminated from the lines of the floats. The watertightness of the floats is obtained by close spacing of the rivets and no packing of any description is employed, such packing being liable to set up corrosion. The float when completed is subjected to anodic oxidation treatment, and as a final protective finish the outside is given a coat of red oxide primer and two coats of pigmented "Lionoil."

Bendix wheel and brake. (Aviation, XXIII., 28/11/27, p. 1286.) (5.55/8359 U.S.A.)

After expensive experimentation and development the Bendix Brake Co., South Bend, Ind, has started manufacture and shipment on a production scale of its first airplane wheel and brake. The brake is a complete unit contained in a disc wheel. It is a special two-shoe servo brake. A number of tests made on production wheels were approved by the U.S. Army Air Corps. According to the manufacturer, Bendix wheels are standard equipment on Fairchild monoplanes and are already in production for a number of other reputable aircraft companies.

Oleo gears for aircraft. (E. E. Aldrin, Mech. Eng.; Nov., 1927, p. I265.) (5.5 I/7759 U.S.A.)

After describing the various oil damping devices for reducing the landing shorks of airplanes, the author presents a theory and test data for the design of the gravity return type of "oleo" landing gear. "This type depends on the flow of oil past an orifice for the shock-absorbing effect. Tests on several forms of orifice using different fluids under a steam hammer gave satisfactory orifice coefficients for design purposes. The landing gears designed with the new information were dropped under weights with different combinations of orifice, wheel and tyre through heights varying up to 42 in. and their performance studied in slow-motion pictures and cards from pressure indicators attached to the gears.

\section{The Handley Page slot in U.S.A. (Aeroplane, XXXIV., 22/2/28.) (7.6/8278 Great Britain.)}

Following on the announcement that the Handley Page automatic slot patents had been acquired by the U.S. Navy, it is now announced that the automatic slot will be fitted to all U.S. naval aircraft in future.

Every type used by the U.S. Navy-training, patrol, pursuit, observation, scouting and bombing-will be submitted to comprehensive tests before all production orders are fitted with the device. The slots on these machines will be set to act at an angle of $10^{\circ}$. In the case of pursuit aircraft, where aerobatics is essential, arrangements will be made for locking the slot.

\section{Safety of aircraft. (Bull. Tech. No. 42, June, 1927.) (16.0/7928 France.)}

This publication represents a very long and comprehensive statement on the present position regarding the policy of increasing the safety of French aircraft. The following are among the points stated most urgently to need a solution :-

Creation of a special air navigation school; improvement of the mancuvring qualities of aeroplanes at low speeds; increase in speed range; instruments to avoid stalling and to give warning of a stall; extension of the use of dual control; 
improvement of the conditions of running and installation of engine accessories ; improvement of piping and flexible joints; development of multi-engine power units; development of and strengthening of fireproof bulkheads, and research work on the use of safety fuels in engines.

Some further aerodynamical relations (without recourse to polar characteristics). (M. Schrenk, 79th Report, in continuation of the 7 ist Report of the D.V.L. German Aerodynamical Inst., Adlershof, Z.F.M., XVIII., I 4/9/27.) (4.2/8352 Germany.)

Empirical relations between height, density and horse-power are given, and from these and from more or less standard aerodynamical formula further relations are worked out.

The polar characteristics are replaced by an empirical parabola which simplifies the expressions. From formulæ for induced resistance an "ideal" aeroplane is calculated and an "ideal" standard power-speed curve derived.

Structural weights and load factors do not appear, so that these relations are purely aerodynamic.

Deduction of the polar of a complete aeroplane from the polar of the principal supporting surface. (M. Panetti, IV. Int. Air Cong., Rome, Oct., r927.) (5. I/7902 Italy.)

Given lift and drag coefficients, for the principal supporting surface and for the tail plane, as functions of the apparent incidence, the resistances are superposed according to certain rules.

Account is then taken of the fact that the principal supporting surface causes the velocity of the air to deviate downwards, diminishing the incidence on the tail plane.

An easy method of estimating this induced incidence is discussed.

The author then draws the curves of resistance, account being taken of the increase of resistance due to the various non-lifting parts of the machine and of the resistance arising from the induction of the principal supporting surface on the tail plane. The author develops these conceptions analytically and shows how to estimate the resistances in a series of simple operations, summarised in a final table.

He further deals with the variation of the aerodynamic action on the fuselage and on the tail plane due to the slip stream of the screw and to the vertical component of the thrust.

A tabular summary shows the succession of the operations. A practical example gives a comparison between the polar of the machine obtained by preserving unaltered the lifting forces and increasing the resistances by a constant and that obtained by taking into account all the factors discussed in the present note. The polar deduced by simple translation, gives a ceiling of $\mathrm{I}, 3 \mathrm{C}^{\circ}$ metres with a velocity of 253 kilometres. The modified polar gives a ceiling of 8,200 metres with a velocity of 223 kilometres.

\section{Structures}

Light weight structures. (Dr. Theodor v. Kármán, Patent 4.53728 (v. 22/6/24), Flugsport, XX., I8/r/28, p. 84.) (5.21/8344 Germany.)

This invention refers to a girder construction characterised by the fact that the outer layers are made of papermache or fibre, the central layers consistin; 5 of a very light weight material like balsa wood or cork. It is claimed that in this way higher resistance towards tension and compression can be obtained than 
in the usual ply wood. There is no reduction in strength due to notches, the material is less affected by water and oil, and being moreover plastic, tubular and other shapes can easily be obtained. In the joining of spars of this type free use is made of glue, not only for fixing the fibre to the internal filling material but also for joining reinforcements of harder wood to the filling material.

Welded aircraft frames. (T. C. Fetherston, J. Am. Weld. Soc., Nov., I927, p. 17. Abstr. in Autom. Abstr., VJ., 20/1/28.) (5.1I/8339 U.S.A.)

All of the trans-Atlantic planes were built of oxy-acetylene welded steel tubing. The Ryan monoplane used by Colonel Lindbergh was made by a California manufacturer using the oxy-acetylene process. The Columbia-Bellanca, used by Chamberlain and Levine, was built entirely of axy-acetylene welded chrome-molybdenum tubing, and the Fokker planes used by Commander Byrd and Lieutenant Maitland are all welded and of chrome-molybdenum and mild steel tubing.

Tensile tests of spot welded tube joints. (A. Rechtlich, 78 th Report of German Aeron. Inst. Adlershof, Berlin. Z.F.M., XVIII., 14/9/27, pp. 393-399.) (Io. I8/840 I Germany.)

Circular tubes of low carbon (silicon manganese) steel are tested without joint and with eleven different kinds of joint. The breaking loads are tabulated and shown as fractions of that of the unwelded tube.

The plain but welded joint reaches 92.5 per cent. and appears as good as any.

Welded aircraft. (R. M. Mock, Convention of the International Acetylene Assocn., I8/11/27. Abstr. in Autom. Abstr., VI., 20/1/28, p. 6.) (10.18/8338 U.S.A.)

The primary members of the metal airplane structure are joined by welding, riveting or bolting. Welding will give a light joint that is cheaper to produce and maintain and in addition it has been proved that a welded joint is strong enough to be safe under all conditions. To-day welding is confined only to certain portions of the airplane structure, though it is rapidly being adapted for nearly all other parts. Practically all airplane manufacturers weld by the oxyacetylene process and to the writer's knowledge there is only one American manufacturer using arc welding on a production basis.

Oscillations in a bridge caused by the passage of locomotives. (Prof. C. E. Inglis,

Procs. Roy. Soc., A. I 8 , No. 779, pp. 60-96.) 5.211/8543 Great Britain.)

The problem is analogous in many ways to the vibration of an aeroplane structure. The analysis developed is therefore of interest to the aeroplane designer and particularly the expressions for deflections, natural periods and forced oscillations.

\section{Airscrews}

New experimental research on helicopter screus. (W. Margoulis, L'Aeronautique, May, 1927.) (17.3/7625 France.)

The author sets up an apparatus consisting of two co-axial airscrew models rotated through gear wheels by a r,ooo watt electric motor fixed to the balance at the Eiffel Laboratory.

The first tests were carried out on the bench with isolated screws and a maximum efficiency of 0.75 was obtained corresponding to an $L / D$ ratio of 0.045 . The second set of tests with the two airscrews coupled and rotating in opposite directions gave an even higher efficiency, 0.825 for the same $L / D$ ratio; 
it: was proved that the best combination is two identical screws rotating at the same r.p.m.

The author studied the static stability of a helicopter and proved that the prevalent instability of existing helicopters with rigid wings is due to the fact that the variation in stress in the case of a helicopter leaning over to one side and hence beginning to side-slip is such as to accentuate this inclination and turn the helicopter right over.

Cavitation in screw propellers. (J. Tutin, M.Sc., Phil. Mag., 7th Series, IV., July, 1927, pp. I7-28.) (5.4I/8354 Great Britain.)

The author challenges Froude's conception of the actuator disc, the properties of which he confuses with the Betz-Prandtl theory. Froude's conception is incomplete and in a sense far fetched, but it is self-consistent and gives an approximate picture of what is happening in the neighbourhood of the screw disc, Betz's theory with Prandtl's correction factor gives a much more complete picture of the physical phenomena. The author appears to be unfamiliar with the original communication which he dismisses with an inaccurate reference.

His new equation (6) is certainly incompatible with the equations of simplified flow due to Froude's actuator. It is difficult to see how it can be reconciled with what we know of the possible varieties of fluid motion. Cavitation is known to appear where the increase of velocity reduces the local pressure below the effective hydrostatic pressure, notably near the tip trailing edge. The author's unfamiliar conceptions of face cavitation and back cavitation do not appear to accord with the observed fact, that cavitation takes place principally at the tip trailing edge, in accordance with well-known physical principles.

Reduction of airscrew tests. (H. Borck, Z.F.M., XVIII., 14/9/27, p. 405.) (5.4I/8353 Germany.)

Part I. appeared on p. 83 and described a logarithmic scale which reducea efficiency curves to straight lines.

In Part II. the same method is applied to representing the fan efficiency at a fixed point, defined as rate of work done in producing blast energy power absorbed.

Simple approximate formulæ are derived, and a nomogram is given for a range of $10-1,000 \mathrm{~h} . \mathrm{p}$. and $\mathrm{I}, 000-100,000 \mathrm{~kg}$. wgt. thrust.

The magnetic field of a helix. (Prof. H. Lamb, Proc. Camb. Phil. Soc., XXI., 1923, pp. 477-48r.) (5.41/7974 Gréat Britain.)

The semi-infinite spiral vortices trailing from the tips of airscrew blades would, if stable, set up a velocity field analogous to the magnetic field of a similar helix carrying an electrical current.

The expressions for a helix infinite in both directions are given by the author in terms of Bessel functions at a point on the axis and at a point not on the axis. The results can be adapted and extended to the semi-infinite helices of the airscrews.

On the fundamental principles of the vortex theory of airscreus. (S. Kawadi, IV. Int. Air Cong., Rome, Oct., 1927.) (5.41/7899 Japan.)

The vortex theory of airscrews allows of the calculation of the air flow. The author by substituting vortex. lines for the blades, determines the induced velocity. He supposes that the spiral vortex lines have the same radius as the elements from which they spring; that their pitch ratio is twice the velocity of advance of the airscrew divided by the angular velocity and finally that the number of 
blades is infinite, in the case of a blade with a high advance velocity developing a moderate thrust. He obtains the fundamental equations and integrates them, getting the expression for the inflow velocity.

$\mathrm{He}$ then shows how to obtain the expression for the induced angle of incidence of each blade element. A further problem is that of determining the effect of a limited number of blades as in actual airscrews.

\section{Fire Prevention}

Automatic fire extinguisher system "Bouillion." (L'Air, I5/2/28.) (16.12/8360 France.)

The article describes fully a type of extinguisher which has been in use on French air lines for some time. It consists essentially of three parts :-

(I) Tank containing the fire prevention liquid.

(2) A sealed bottle containing air under pressure.

(3) A trigger arrangement for perforating the sealing capsule of the air bottle, thus putting the fire extinguishing liquid under pressure and projecting it through suitable nozzles on to the seat of the fire.

The perforation of the capsure on the air bottle can be carried out either by hand or automatically; the automatic release is by means of a wire which is stretched through those parts of the aircraft which require protection. The wire has interposed in its length links made of fusible alloy. In the event of a fire or abnormal rise in temperature the links melt and release the trigger.

\section{Photography and Survey}

\section{INSTRUMENTS}

Optical systems for photographic surveying. (British patent 282422, Ill. Off. J. (Pats.), 15/2/28, p. 7380.) (14.21/8362 Great Britain.)

A multiple camera for aerial photography consisting of several separate cells having objectives arranged in a circle round a central cell having an objective or round an axis of symmetry, and having a common focal plane, is characterised by the interposition of a trilateral prism with two reflecting planes in the path of the rays from each of the objectives in the circle of cells "in such a manner that after transforming the photographs on the basis of a common direction of exposure, the targets photographed by all the cells form an area without gaps and without re-entering angles, representing a continuous picture such as is obtained by wide-angle exposure made with a single objective."

Experiments in air photography by night carried out at Le Bourget. (L'Echo de Paris, 21/2/28.) (14.4/8403 France.)

An experiment in air photography by night was carried out at Le Bourget in the presence of members of the S.T.Ae.

The apparatus includes a shell containing I $\mathrm{kg}$. of magnesium which bursts Ioo metres from the point to be photographed and lights up the area for. I/5oth of a second. The test was not entirely satisfactory as the drift was greater than had been expected and the spot to be photographed was not adequately illuminated.

\section{Wireless}

Short undamped electrical waves. (K. Kohl, Ann. d. Phys., LXXXV., 4th Series, 1928, pp. 1-62.) (13.7/8361 Germany.)

The object of the research is the excitation of the shortest possible undamped waves with maximum encroy and the investigation of the electron mechanism. 
After reviewing previous experimental work, further experiments are described leading to the excitation of waves of $30 \mathrm{~cm}$. wave length. Theoretical discussion and an examination of the quantitative measurements lead to the conclusion that wave lengths of $10-15 \mathrm{~cm}$. are practicable. A bibliography of 54 references is given.

Disturbances caused by ignition circuits in the wireless circuits on aeroplanes. (F. Franck, IV. Int. Air Cong., Rome, Oct., 1927.) (8.93/7893 Italy.)

The disturbances are tolerable when the wireless circuit is employed in the ordinary way at low frequency, but they are more damaging in high frequency circuits which are becoming more and more used in aerial navigation. The magnetic field is felt up to two metres distance from the ignition and magnetic circuits. There are two remedies, by suppressing the disturbing fields in the ignition circuit, or by protecting the receiving apparatus from them. In the first case the magneto and its circuits nust be completely isolated. The author describes various systems avoiding undue complication and weight. In the second case it is proposed to construct receivers with entirely symmetric circuits, not sensitive to the magnetic field and to isolate these circuits.

He discusses the frequency variation in the magnetic field produced by the ignition spark.

\section{Television}

Wire transmission system for television. (D. K. Gennett and E. I. Green, Bell - Sys. Tech. J., VI., Oct., 1927.) (г3.8/7910 U.S.A.)

This paper deals with the transmission problems which were met and solved in connection with providing wire circuits from Washington to New York for the television demonstrations which took place on April 7 th, 1927, and following. For transmission of the television images a single transmission channel was set up combining the frequency ranges usually assigned to telegraph, telephone and certain carrier channels. The special line requirements were met so successfully that the television images transmitted from Washington were indistinguishable from those transmitted locally.

Synchronisation of television. (H. M. Stoller and E. R. Morton, Bell Sys. Tech. J., VI., Oct., 1927.) (I3.8/791 I U.S.A.)

Synchronisation of television is the problem of holding two scanning discs so that their phase displacement is always less than four and one-third minutes of arc. A 240-pole synchronous motor of the variable reluctance type is used as a basis. Coupled to it a direct current motor carries the steady component of the load. Hunting is eliminated by a condenser in series with the two synchronous motors whose capitance is slightly less than that required to tune the circuit.

As the motor might lock into stop in any of 120 possible angular positions, only one of which would give the proper phase relations, a two-pole motor, with only one locking position, was provided by tapping the armature of the direct current motor at two points and bringing out the leads to slip rings. This was used for synchronising while the 240-pole motor, connected subsequently, held the close synchronism required. The discs rotate at 1062.5 r.p.m., which gives 17.7 cycles on the two-pole and 2,125 cycles on the $24 \mathrm{C}-$ pole motor.

For transmission the synchronising current is attenuated to a level of . 6 milliwatt and amplified at the receiving end. The 17.7 cycle current is an undesirably low frequency for transmission over telephone cables and so is used to modulate a 760 cycle current through a polarised relay. This is demodulated 
at the receiving end, where a polarised relay by interrupting a local battery current gives a rectangular wave which acts through vacuum tubes on the field of the direct current motor.

Television. (H. E. Ives, Bell Sys. Tech. J., VI., Oct., 1927.) (13.8/7912 U.S.A.)

The chief problems presented in television are the resolution of the scene into a series of electrical signals of adequate intensity for transmission; the provision of a transmission channel capable of transmitting a vide band of frequencies without distortion; means for utilising the transmitted signals to recreate the image in a form suitable for viewing by cne or more observers; arrangements for the accurate synchronisation of the apparatus at the two ends of the transmission channel.

Radio transmission system for television. (Edward L. Nelson, Bell Sys. Tech. J., VI., Oct., 1927.) (13.8/7909 U.S.A.)

Starting from the general requirements imposed on the transmitting medium, this paper discusses the engineering of a radio system for television purposes and describes the radio facilities actually employed for the recent Bell System demonstration. The tests to which the system was submitted to determine its suitability are outlined and the measured frequency response characteristics are shown. An interesting phenomenon due to multi-path transmission, the production of positive and negative secondary images is reported. A brief series of experiments concerned with the transmission of both voice and image "on a single wave length" is also described.

The production and utilisation of television signals. (F. Gray, J. W. Horton and R. C. Mathes, Bell Sys. Tech. J., VI., Oct., I927.) (13.8/7908 U.S.A.)

The design of a television system, once the fundamental principles are understood, involves a detailed consideration of the methods by which the several important functions are to be performed.

(x) In the present system the initial signal wave is obtained by sweeping a spot of light over the subject in parallel lines completely scanning it once every I 8 th of a second. The light reflected is collected by large photn-electric cells which control the transmitted current. At the receiving station the picture current controls the brightness of a neon lamp from which the received image is built up by means of a small aperture moving in synchronism with the spot of light at the transmitting station. .For presentation to a large audience television images may be produced by a neon lamp in the form of a grid having a large number of separate electrodes. A high frequency excitation controlled by the picture current is distributed to the successive electrodes in synchronism with the spot of light at the transmitting station.

(2) Space and time variations in the reflecting power of the subject are translated into time variations in signal strength. For design purposes these time variations are represented by component frequencies, a minimum band of which must be properly transmitted to insure an adequate reproduction of the image. Within this band there must be maintained a certain degree of iniformity in the efficiency of transmission of the separate components. Also their phases must not be permitted to shift unduly in relation to each other.

(3) The design of the terminal amplifiers is based on the quantitatively determined characteristics of the photo-electric cells and of the neon lamps as well as on the limits imposed by the transmission study and by the characteristics of available transmission media, whether telephone line or radio system. The circuits employed at the transmitting station furnish an amplification such that 
the power delivered to the transmission medium is $10^{15}$, the power received from the photo-electric cells.

\section{Engine Indicators}

Piezo electric indicator for high-speed internal combustion engine. (Fujio Nakanishi, J. Soc. Mech. Eng., Tokyo, XXVII., 1925, p. 96. Abstr. in Jap. J. of Eng., V.) (8.632/7922 Japan.)

Piezo-electricity of quartz is utilised to measure the rapidly varying pressure in the cylinder. The electric charge due to the pressure is applied to the grid of a valve, and the plate current which varies as the grid voltage is recorded with an oscillograph. By this method indicator diagrams can be taken with sufficient sensitivity and accuracy even at the speed of 5,000 r.p.m. or more. Another merit is that the record can be taken at any distance from the engine. (Abstractor's Note.-The calibration of the instrument presents great difficulties.)

Piezo electric indicator for high-speed internal combustion engine (Japanese). Masatoghi Okochi, Shitiryo Mashimoto and Shinsaka Matsui, Bull. Inst. Phy. Chem. Research, Tokyo, IV., 1925. Abstr. in Jap. J. of Eng., V.) (8.632/7925 Japan.)

The pressure variation in the cylinder of a high speed internal combustion engine is photographically recorded by a string galvanometer. The string is. charged by the piezo-electricity of quartz corresponding to the pressure in the cylinder.

\section{Hairsprings}

Notes on the manufacture and properties of hairsprings. (H. Moore and $\mathrm{S}$. Beckinsale. Pamphlet issued by the Inst. of Metals.) (6.731/7914 Great Britain.)

The function and essential properties of hairsprings and control springs are discussed. The respective merits and disadvantages of steels, ferrous alloys (e.g., elinvar), and non-ferrous metals and alloys as hairspring materials are indicated. To raise the elastic limit to the required degree, hardening by heat treatment or by cold working is necessary, but all hardening operations are liable to produce a state of imperfect elasticity detrimental to the spring. The use of low temperature heat treatments to restore elasticity after cold working (drawing, rolling and the coiling of the spring) is described. Steel hairsprings are subject to corrosion, but elinvar is highly resistant. Some details of the manufacture of phosphor bronze and other hairsprings' are given and the selection of material for hairsprings required to have a low electrical resistance is discussed.

\section{Optics}

Simplified presentation of stereograms. (N. Deisch, J. Sc. Inst., IV., No. Ir.) (I 4.0/7917 Great Britain.)

The article refers to the possibility of obtaining a stereoscopic presentation of a picture by looking at two pictures without optical aid.

\section{Materials}

\section{Hardness and Tensile Strength of Materials}

The elastic limit and figure of merit of light alloys. (A. Schroeder, Z.F.M., I 4/3/28, p. 105.) (I0.2 I $/ 8534$ Germany.)

It has been customary to compare the performance of light alloys on a basis of saving in weight for the same tensile strength. This comparison is fallacious 
since no consideration for safety is given. What is required is not a comparison of ultimate tensile but infinite life under reversal of stress. This point is closely related with the elastic limit of the material. This elastic limit has to be determined with great accuracy in order to render the comparison of value.

The elastic limit. (G. Welter, Prize Essay contributed to the W.G.L., Z.F.M., XVIII., 28/9/27, p. 418.) (II.24/8340 Germany.)

The author discusses the influence of temperature, time, nature of loading, etc., such as occur in aeronautics, particularly alternating loads.

He criticises the usual type of stress strain diagram and introduces much more open diagrams with extension co-ordinates magnified about 50 and 500 times.

This he calls the "fine measurement" diagrams, and claims more accurate diagnosis of the properties of the materials tested, particularly of the true elastic limit.

He comes finally to the conclusion that the elastic limit thus determined by "fine measurement" is the true criterion of the working properties.

(Abstractor's Note.-This conclusion has been vigorously contradicted.)

Contribution to the problems of hardening. (J. Sachs, Z.f.Tech. Phys., VIII., I927, pp. 132-I 4 I.) (10.11/781 + Germany.)

The tests reported on in this paper were carried out to check Prandt1's plasticity theory (cf. Z.f.A.M.M., I., I921, pp. 15-20), and consisted of cupping tests, using a prismatic tool, on bodies with top surface of different shape made of mild steel and copper. The nature of the plastified area was determined by observation of the recrystallisation occurring on annealing and by means of flow figures, also the variation of resistance to penetration with increasing depth of cup. In the case of a body with horizontal top surface, the area of recrystallisation seen in section forms roughly a circle tangential to the top surface at the edge of the cupping tool. The result of the investigation shows that the structure does not conform to Prandt1's theory, but confirms Nadai's calculated distribution (cf. Z.f.A.M.M., III., I921, pp. 20-28) of the elastic stresses under loads imparted by a cupping tool. The measurements of the resistance to penetration were also not in good agreement with Prandtl's theory.

\section{Light Alloys-Physical Characteristics}

Light alloys. (Dr. W. Claus, Motorwagen, XXX., Io/12/27, pp. 7 I3 $^{3}$ and 717.) (10.21 $/ 8342$ Germany.)

In a review of the light alloys exhibited, reference is made to a new alloy called alneon, used by Junkers and Siemens for the crankcases of their aerial engines. This alloy is supplied by $\mathrm{R}$. Rautenbach, Solingen, Germany, and has the following main characteristics :-

Elastic limit, 7.5 to $12 \mathrm{~kg} \cdot / \mathrm{sq} . \mathrm{mm}$.

Ultimate tensile, 20 to $30 \mathrm{~kg} . / \mathrm{sq} . \mathrm{mm}$.

Extension, 3 per cent.

Hardness figure, 100 to 150.

Density, 2.8 to 3.1 .

A similar alloy called noonalium is characterised by maintaining its strength up to high temperatures and is chiefly used for cylinder head casting. Other exhibits of new alloys included a chassis made of lantal and forged propellers made of aeron and skleron. Other better known alloys like electron and duralumin were represented in numerous examples of engine parts. 
Thermal expansion of beryllium and aluminium-beryllium alloys. (P. Hidnert, Bur. St. Sc. Paper No. $565,29 / 10 / 27$.$) (to.21 / 85^{68}$ U.S.A.)

The investigation described in this paper was undertaken because no data on the thermal expansion of beryllium or any of its alloys were available. The paper gives results of the linear thermal expansion of beryllium (98.9 per cent.) and five aluminium-beryllium alloys containing various percentages of beryllium ( 4 to 33 per cent.). Expansion determinations were made over various temperature ranges between $-120^{\circ}$ and $+700^{\circ} \mathrm{C}$. on a sample of beryllium and between room temperature and $500^{\circ} \mathrm{C}$. on the aluminium-beryllium alloys. The expansion curves of beryllium and aluminium-beryllium alloys are shown and discussed. The average coefficient of expansion of beryllium is $12.3 \times 10^{-6}$ per degree centigrade between 20 and $100^{\circ} \mathrm{C}$. Beryllium expands considerably less than the other elements of sub-group IIB (magnesium, zinc, cadmium and mercury). The coefficients of expansion of the aluminium-beryllium alloys decrease with increase in the beryllium content. On a second heating the coefficients are generally larger than the corresponding values obtained in the first heating. The relations between the coefficients of expansion and the chemical composition were compared with the equilibrium diagram obtained by Oosterbeld, and were found to be in agreement with the theory,

Progress in the utilisation of light alloys on board ship. (B. R. Schulz, Z. Metallk., March, I928, p. 122.) (I0.21/8536 Germany.)

As a result of the Washington Conference the dead weight of warships has been limited. It has given a great impetus to the utilisation of light alloys. For castings silumin and for forgings duralumin are already receiving wide application, the latter especially in the U.S. Navy.

For parts specially subjected to the action of sea water, precautions to minimise corrosion have to be taken. This can either be done by the choice of suitable alloys or by the provision of a protective coating. The German alloy known as K.S. possesses remarkable resistance towards corrosion. This alloy contains 3 per cent. Mn, $2 \frac{1}{2}$ per cent. Mg, .5 per cent. Sb, the rest being aluminium. The resistance to corrosion is attributed to the antimony. As to the provision of protective coatings, the author favours the Jyropka process which consists of an electric deposition of chromium (German patent No. 442766). Recent experiments have shown this method to be superior to any other.

Tests to determine corrodibility of magnesium alloys. (A. Portevin and E. Pretet, Comp. Rend., CLXXXV., I I/7/27, pp. I 25-127.) (10.27/7643 France.)

The rate of dissolution of magnesium alloys in various acid and saline solutions was determined comparatively using three methods. That based on the determination of the loss of weight is not satisfactory as errors may arise when a film, which must be removed, is deposited on the test pieces. Measurement of the gases given off (as used by Ostwald, Centnerszwer, Chaudron and Wache) when carried out on test pieces in the form of plates $20 \times 15 \times 2.5 \mathrm{~mm}$. with edges protected with a film of wax, gave excellent results.

Measurements by Mylius' method; in which the increase in temperature resulting from the action of the reaction agent on a test piece of given dimensions is measured, gave results agreeing on the whole very well with those of method two for the same reaction agent. Pure $\mathrm{Mg}$ has the lowest corrodibility in the presence of all the reaction agents used and the presence of Si has a considerable influence on the corrodibility. The alloys with $\mathrm{Ni}$ and $\mathrm{Cu}$ were found to be the most sensitive to a saturated solution of $\mathrm{No} \mathrm{Cl}$; alloys with $\mathrm{Cu}$ corrode very rapidly in a solution of 0.5 per cent. of $\mathrm{Mg} \mathrm{Cl}_{2}$. All the magnesiun alloys, unlike the Al alloys used industrially, were found to be almost insensitive to 0.5 per cent. solution of soda. 
The extrusion of elektron in the form of rods. (Dr. Ing. Schmidt, Z. Metallk., XIX., Oct., I927, p. 378.) (10.21/7670 Germany.)

The author describes very fully experiments carried out to investigate the flow of metal occurring during extrusion processes. For this purpose special experimental bodies were built up consisting of alternate discs of elektron, and an alloy containing 5 per cent. zinc. On etching the experimental body with hydrochloric acid, the zinc alloy produces dark markings on which the flow ines can be followed. By this means the most economical method of extrusion was investigated both for solid cylinders and tubes, as well as the effect of extrusion on the tensile strength. The article is fully illustrated.

New light aluminium alloys C6 and MC (Japanese). (Tomojiro Tanabe, J. Soc. Mech. Eng., Tokyo, XXVIII., 1925, p. Io2. Abstr. in Jap. J. of Eng.,

V.) (Io.21/7948 Japan.)

The author prepared two new series of strong light aluminium alloys by special heat and mechanical treatment- $\mathrm{C} 6$ alloy, 6 per cent. copper and 94 per cent. aluminium; and MC alloy, I-2 per cent. copper, $0.5^{-1}$ per cent. magnesium and aluminium balance. The author claims for the new alloys mechanical qualities rather superior to those of duralumin.

\section{Armco Iron}

Observations on the microstructure of the path of fatigue failure in a specimen of Armco iron. (Francis F. Lucas, Bell Tel. Lab. Repr. B-257, June, I927.) (10. I 1 /7626 U.S.A.)

A co-operative study under the auspices of the National Research Council.

The paths of fatigue failures in specimens of Armco iron are shown. Noninetallic inclusions act as "stepping stones" for the crack. Inclusions seem to influence the origin and trend of the crack. Grain boundaries do not appear to be a potential source of weakness.

\section{Corrosion}

The corrosion of aluminium. (Prof. W. Guertler, Z. Metallk., March, i928, p. 104.) (10.27/8535 Germany.)

Several years ago a special committee was formed in Germany to investigate the corrosion of aluminium. The committee worked in close conjunction with the German breweries and dairies, which utilise aluminium on a large scale. All questions of corrosion occurring in these industries were investigated in special laboratories and the present is a report of the committee's findings.

After dealing generally with the theory of corrosion the author deals with the effect of the physical condition of the surface as well as the presence of chemical impurities on the corrosion. The particular way in which the metal is worked is of enormous influence on its subsequent behaviour. The metal is only suitable for the storing of such liquids as by their action form a protective coating. Such liquids are water, wine, beer and milk. Alkalies and chlorides are extremely destructive. The author describes special apparatus designed by him for studying corrosion. Of special interest is the study of the formation of pinholes in metal sheets.

\footnotetext{
Prevention of embritlement of duralumin. (U.S. Bur. St. Misc. Pubcn. No. 8r.) (10.27/7939 U.S.A.)

Duralumin is subject to intercrystalline corrosion resulting in embrittlement, markedly reduced by rapid quenching in cold water during heat treatment, instead of in hot water or oil. Pure aluminium is not susceptible to this type of corrosion and laboratory tests, supported by a year's exposure tests, indicate that a coating of pure aluminium effectively protects duralumin from intercrystalline attack. The method is now being used commęrcially.
} 
The theory of metallic corrosion in the iight of quantitative measurements.

(G. I). Bengough, J. M. Stuart and A. R. Lee, Procs. Roy. Soc., A., CXVI., A.774, p. 425.) (10.27/8343 Great Britain.)

The principal object of the present research is the discovery of a satisfactory way of measuring the corrosion of metals in water and dilute salt solutions, and the use of it to test the adequacy of the newer electro-chemical theory of cortosion as applied to such media. The theory suggests that a large number of factors can influence the rate of corrosion, but does not indicate quantitatively their relative importance in given conditions, in fact, the theory is based at present upon qualitative or only roughly quantitative measurements. It is desirable, therefore, that a determined attempt should be made to place it upon a sounder basis, on account, both of the inherent interest of the theory and of its importance in technical problems of steadily increasing insistence.

The present communication is the first portion of an extensive research; it is divided into three sections, the first gives an outline of the theory as understood by the authors; the second, a brief review of the kind of measurement upon which it rests ; the third, an improved method of measuring corrosion as applied to the metal zinc, together with an interpretation of the results so far obtained.

\section{Glass}

Transmission of ultra-violet light through glass. (Bur. St. Tech. News Bull. No. 126, Oct., I927.) (10.51/7919 U.S.A.)

It is stated that it has been demonstrated beyond all reasonable doubt that all the new glasses now being marketed for transmitting the ultra-violet rays, undergo a photo-chemical action and decrease greatly in transparency to these rays when exposed to ultra-violet radiation. Glasses which transmit 15 to 25 per cent. at $0.28 \mathrm{U}$ when new, decrease in transmission to less than 5 per cent. after a few hours exposures to the mercury arc or a few weeks to the sun.

\section{Fabrics}

Ultra-violet transmission of fabrics. (Bur. St. Tech. News Bull., No. I26, Oct., 1927.) (10.41/7920 U.S.A.)

Measurements have been made on close weave and open weave fabrics, submitted to the Bureau as approximately pure. cellulose (viscose and cellulose acetate rayons). After eliminating the light transmitted through the openings between the threads, the following ultra-violet transmission coefficients have been deduced :--

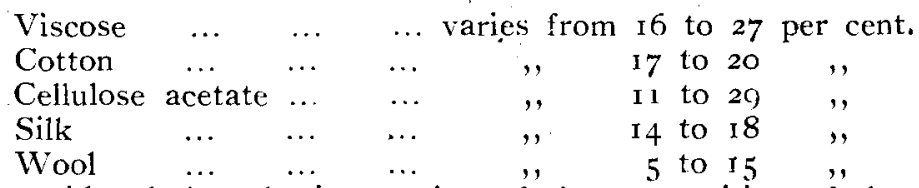

It is considered that the importance of the composition of the material in this respect has been over-estimated.

Textile fabrics-ultra-violet transmission. (K. Hess, J. O. Hamilton and M. Justin, J. Agric. Res., XXXV., 1927, pp. 251-259. Abstr. by B.C.I.R.A.) (10.4I/7935 Great Britain.)

An attempt has been made to determine the relative ability of wool, silk, linen and cotton fabrics to protect the skin from the ultra-violet rays of direct sunlight and of artificial light sources. The lightest weight, plain weave, wool fabric was chosen and was matched as nearly as possible in weight and number of picks and ends per inch with similar fabrics of silk, linen and cotton; only white fabrics were used. The ratio of the lime required to sunburn the skin through the selected fabrics to the time required to produce a sunburn of equal 
intensity on the unprotected skin under the same controlled conditions was determined. This ratio was accepted as the coefficient of protection of the fabric. The difference in protection, not due to difference in construction, was accepted. as the coefficient of protection of the fibre. The data tend to prove that protective ability depends primarily on the percentage interspace due to weave, but that the vegetable fibres have a lower coefficient of protection than the animal fibres. As temperature is a factor in the burning of the skin the greater conductivity of cotton and linen as compared with silk and wool might to some extent account for the higher protective value of silk and wool.

The influence of atmospheric conditions on textiles. (Sommer, Leipzige Monatschrift der Textilindustrie, 1927 , Nos. I to 4.) (10.41/78 I 3 . Germany.)

A report of experiments carried out to test the effect of exposure to light, air and weather on fabrics of different kinds, samples of which were exposed for a year in a clear atmosphere and in an atmosphere polluted by the neighbourhood: of a railway. Changes in appearance, weight, chemical properties and strength were noted each quarter. On the whole the strength tests gave the most useful: measure of the deterioration.

The general conclusions are that the deterioration occurring with exposure to the weather mainly affects the exposed surface and is due to the short wave (mainly ultra-violet) rays of the sun. The presence of moisture hastens deterioration, especially in the case of wool and best fibre fabrics, as can-be proved by comparison with results of earlier tests in which fabrics were exposed only to the ultra-violet rays produced by a mercury vapour lamp. The nature of the atmosphere is also a factor of appreciable importance; the test pieces in the considerably clearer atmosphere of Neubabelsberg deteriorated less rapidly than those at Dahlem. Calculating the sensitivity of the fabrics to weather by the number of hours of sunshine causing the initial strength to be reduced by one half, when the fabric may be considered as no longer serviceable, it is found that silk is the most sensitive, less than 200 hours, the figures for the other kinds of fabric being jute 400 hours, artificial silk goo hours, cotton 940 hours, flax 990 hours, hemp r, I00 hours, natural wool about r, I20 hours. Chromed wool was found to be the most durable with 1,900 hours.

Moisture content of yarns. (Sommer, Spinner u. Weber, 1927, Nos. 17 and 18.) (10.41//281 2 Germany.)

The author has made a useful compilation from well-known works on the subject of the moisture content of yarns and its importance in the production, conditioning and testing of textiles. Taking as a basis Muller's fundamental work on the variation of the hygroscopic humidity of yarns with the relative humidity of the air, the most important results, in particular the works of Höniz and Obermiller, are compared. Obermiller's criterion-i.e., the absorption of moisture with air of 65 per cent. relative humidity-for the measurement of the legally permissible amount of moisture appears less suitable than another suggestion in which the yearly average of the humidity of the air of the countries of origin is taken as the criterion. The influence of the moisture content of yarns in the determination of the weight and count and on the strength characteristics makes it necessary to store the yarn for a considerable time before testing under constant standard $(65$ per cent.) humidity conditions.

\section{Inspection of Metals by X-Rays}

Recent application of X-rays. (V. E. Pullim, J. Sc. Inst., Feb., I928, p. 4I.) (I I.26/8542 Great Britain.)

Reference is made to the work at Woolwich on the physical structure of explosives. With respect to radiographic inspection of metals, the need of 
extremely high voltages is emphasised. A limit is found in practice at about 300,000 volts permitting penetration of $4 \frac{3}{4} \mathrm{in}$. of steel. The article contains -photographs of apparatus and typical radiographs.

\section{ARMAMENT \\ 36 Experiments on Movement of Bullets in Water}

The influence of free surface and fixed walls on fast moving bullets in water.

(C. Ramsauer, Ann. d. Phys., No. 22, I927, p. 71.) (9.16/8539 Germany.)

The phenomena of ricochet is investigated experimentally for different angles of incidence. It was found that a high velocity bullet, moving in water parallel to the free surface is displaced towards the free surface. In the case of motion parallel to a fixed surface, however, the path of the bullet is displaced away from the surface. In either case, the force of displacement was found to be proportional to the square of the velocity of -the bullet. A theoretical explanation of the phenomena has been attempted.

Motion produced in water by the passage of a fast moving bullet. (C. Ramsaver, Ann. d. Phys., No. 22, 1927, p. 697.) (9.16/854I Germany.)

A method is described for photographing the phenomenon of the bullet striking stationary water. The photographs show the formation of a cavity behind the bullet. This cavity expands regularly until the water is disrupted with explosive force. The diagrams obtained were utilised to determine the water velocities as a function of the velocity of the bullet and of the distance from the path of the projectile. A theoretical explanation of the phenomena is attempted and a comparison is made with previous experiments of a similar nature.

\section{Testing Aircraft Armament}

Testing aircraft armament. (Lt. G. H. Steel, Air Corps, U.S.A., Army Ord., Jan.-Feb., I928, p. 229.) (9.0/8526 U.S.A.)

The article describes the method of testing of aircraft armament carried out at Aberdeen Proving Ground, located near the head of Chesapeake Bay, four miles from Aberdeen, Maryland. The proving ground comprises an area of :approximately 35,000 acres. On a large bombing field the effect of land impact. of bombs is studied. A portion of the field has been concreted to test the strength of bomb cases whilst water impact can be studied in Chesapeake Bay. The trajectory of the bomb is studied by means of special camera obscura; tests are also carried out on the proving ground on ground flares, and ground synchronisation, in connection with the latter the importance of a rigid connection between the gun and the synchronising motor is emphasised. A mounting which vibrates or allows movement will cause a give in the connection between the gun and the synchronising motor resulting in misfire.

\section{Airships and Balloons}

\section{Miscellaneous}

The new Zeppelin airships. (Flug, Oct., I927, p. ro.) (12.13/8395 Germany.)

The article describes the new Zeppelin airship, L.Z. 127 , intended for the service between Spain and the Argentine. The airship has a capacity of ${ }_{1} 15,000$ cubic metres. The length of the ship is 235 metres and its maximum diameter is $3^{0.5}$ metres. The ship has sleeping accommodation for 40 passengers in a separate gondola, the accommodation for the crew being inside the airship proper. The airship is driven by six Maybach engines of $400 \mathrm{~h}$.p. each. As fuel, a mixture of ethylene and butane is used; this has a density very nearly equal to that of air, and is stored in ballonets inside the airship. Fuel consumption does not thus cause a change of trim. The useful load is stated to be 20 tons and the radius of action $r_{4}, 000$ kilometres. 
The giant airship. (B. Pochmammer, Luftfahrt, XXXI., z/1o/27, p. 296.) (1 2.2/7668 Germany.)

The author states, as well known, that the proportion of structural weight in relation to the air displaced diminishes as the size of the airship is increased. It is thus possible either to carry a larger percentage of useful load or, on the other hand, to increase the factor of safety of the structure. In that direction the author indicates lines of development.

The new high altitude balloon, Bartsch von Sigsfeld. (Z.F.M., XVIII., 28/11/27,. p. 5 ${ }^{\text {I } 3 .) ~(I ~} 2.5 / 7854$ Germany.)

The article describes the special features of this balloon, which has a nominal capacity of 9,500 cubic metres. It is designed to operate at high altitude, above 30,000 feet. Besides making physiological tests on the effect of high altitude on the human body, special attention being given to the effect of radiation, it is intended to investigate the performance of a small single cylinder air-cooled engine which can be carried inside the car of the balloon. The engine can have its compression ratio altered during the running and it is fitted with a super-. charger. Accurate power measurements can be taken during flight.

\section{Meteorology}

Measurement of atmospheric potential gradient carried out from an airship.

(A. Wigand, Ann. d. Phys., 1928, No. 3, p. 333.) (6.23/8394 Germany.)

The object of the experiment was to study the rise of electric potential of the airship engines as well as difference of potential relative to the airship generally. The charging up of the engines is mainly due to the friction of the exhaust. The Maybach engines of the new Zeppelin L.Z. I 26 only showed a small amoun of electrical charging. It is possible that the gaseous fuel employed in this. case is of influence. The article deals generally with the dangers arising in airships due to electrical discharges. It is stated that by using suitable instruments it is possible to obtain warning as to any dangerous rise in potential. The approach of thunder clouds can be distinguished at a distance of several miles, and the danger can be minimised by avoiding them.

Glare, visibility definition. (M. Luckiesh, Sc. Abstr. B., XXX., 1927, p. 519, from Trans. Am. Illum. Eng. Soc., XXII., 1927, pp. 542-546, abstracted by B.C.I.R.A.) (6.23/7934 U.S.A.)

The factors entering into glare and visibility are treated and definitions are suggested for visibility, threshold, glare, veiling, field brightness, adaptation brightness, contrast sensitivity, and safety factor of visual contrasts, this being defined as the ratio of the actual difference in brightness between an object and its background to the minimum difference in brightness at which the object may just be seen.

\section{Acoustics}

Sound meter. (H, Barkhausen, Z.V.D.I., LXXI., r5/10/27, pp. I 47 I-I 474.

Abstr. in Sc. Abstr., XXXI., Pt. I., 25/1/28, p. 39.) (6.76/8527 Germany.)

Discusses the difference between physical and physiological intensity of sound and describes a form of sound meter for technical use. Details and practical examples are given.

Notes on abnormal distribution of sound in air. (E. Wieshert, Gott. Nach., I926, No, 3, pp. 20I-2II. Abstr, in. Phys. Ber., I/2/28, p. 224.). $(6.76 / 8390$ Germany.)

The report describes the results of experiments which demonstrate that at an altitude of 30 to 40 kilometres the velocity of sound increases suddenly in an upward direction. The reason for this is stated by the author to be a sudden increase in atmospheric temperature with altitude. The ultra-violet rays of the 
sun are supposed to change $\mathrm{O}_{2}$ into $\mathrm{O}_{3}$ and this causes an increase in temperature which at 60 kilometres is supposed to approach again that of sea-level.

The measurement of sounds in aeroplanes. (H. Fassbender and K. Kruger, Z. Tech. Phys., VIII., 1927, pp. 277-282. Abstr. in Nach. f. Luft., VIII., 28/7/27.) (6.76/7642 Germany.)

A suitable instrument to measure the intensity of sounds is still lacking, but valuable information can be obtained by using the Barkhausen-Siemens acoustic meter. It consists of a buzzer (the current through which is so regulated that it just lights a lamp), and a single ear phone, excited by the buzzer across a potentiometer, the note heard in the phone being used as a standard of comparison for the extraneous noise perceived by the other ear. The fraction of P.D. delivered to the ear phone increases as powers of two and the value is selected in such a way that the sounds heard through the ear phone and througa the other ear (e.g., the sound intensity in a $W / T$ headphone) are of equal intensity.

The intensity of the sound varies considerably with the position of the observer.

In the case of the Rohrbach-Roland it is lowest in the passenger cabin. When the observer is sitting in his seat, with his head outside in the relative wind the sound intensity is highest, being 64 times the intensity in the cabin; when bending over sideways towards the centre of aircraft the sound is eight times louder, and in a normal posture 16 times louder than the sound in the cabin.

Sound absorbing gypsum plaster. (U.S. Bur. St. Misc. Puben. No. 8r.) (5.6I/794I U.S.A.)

Ninety per cent. of the acoustical defects of auditoriums, theatres and churches may be remedied by a sound-absorbing plaster. A gypsum plaster composed of two parts of volcanic tufa, one part sand and one part of calcined gypsum and containing two per cent. by weight of the calcined gypsum of a mixture of calcium carbonate and potassium alum in molecular proportions with retarder has been found to have the sound-absorbing properties desired.

Recent applications of sound propagation to geo-physics and cognate tcchnology.

(E. G. Richardson, Science Progress, No. 86, Oct., 1927.) (6.26/8595 Great Britain.)

The following subjects are dealt with:-

(a) The phenomena associated with the propagation of sound resulting from large explosions such as those arranged at Oldebrook, La Courtine and Jucterbog are :-

(i) Abnormally high velocities in the neighbourhood of the explosion.

(ii) A zone of normal velocity and audibility.

(iii) A zone of complete silence, and

(iv) A zone of abnormal audibility in which the sound re-appears with renewed intensity.

The arguments for attributing the abnormal audibility to the inversion of the path of the sound ray at heights of the order of $50 \mathrm{~km}$. are given. It is pointed out that the most probable cause of this phenomenon is the existence of a temperature inversion at about $\mathrm{I} 7 \mathrm{~km}$. above which the temperature rises with height and reaches the surface temperature at $35 \mathrm{~km}$.

(b) The principles of sound ranging based upon the nature of the propagation of sound in the lower air are given.

(c) The application of the technique of sound measurement to the determination of depth in water and to the height of aircraft is described. The principle of the Bohm apparatus, dealt with previously in these abstracts, is given. 